NBER WORKING PAPER SERIES

\title{
HETEROGENEOUS INVESTORS AND THEIR CHANGING DEMAND AND SUPPLY SCHEDULES FOR INDIVIDUAL COMMON STOCKS
}

\author{
Jung-Wook Kim \\ Jason Lee \\ Randall Morck \\ Working Paper 10410 \\ http://www.nber.org/papers/w10410
NATIONAL BUREAU OF ECONOMIC RESEARCH 1050 Massachusetts Avenue
Cambridge, MA 02138
April 2004

We thank Hyeon Kee Bae, Mark Huson, Aditya Kaul, Ki Bong Lee, Vikas Mehrotra, Barry Scholnick, Andrei Shleifer, Jeremy Stein, students in Andrei Shleifer's behavioral finance seminar course at Harvard University, and seminar participants at the University of Alberta for helpful comments. We gratefully acknowledge financial supports provided by the Social Sciences and Humanities Research Council of Canada. The views expressed herein are those of the author(s) and not necessarily those of the National Bureau of Economic Research.

(C2004 by Jung-Wook Kim, Jason Lee, and Randall Morck. All rights reserved. Short sections of text, not to exceed two paragraphs, may be quoted without explicit permission provided that full credit, including (C) notice, is given to the source. 
Heterogeneous Investors and their Changing Demand and Supply Schedules for Individual Common Stocks Jung-Wook Kim, Jason Lee, and Randall Morck

NBER Working Paper No. 10410

April 2004

JEL No. G0

\title{
ABSTRACT
}

Using 550 million limit orders submitted in the Korea Stock Exchange, we estimate demand and supply elasticities of heterogeneous investor types and their changes around the Asian financial crisis. We find that domestic individuals have substantially more inelastic demand and supply curves than domestic institutions and foreign investors. The crisis permanently reduced price elasticities of domestic individuals by $50 \%$ but had no effect on those of foreign investors. Institutional changes restricting margin purchases, implemented after the crisis, seem particularly important in explaining the dramatic drop. Information heterogeneity, availability of close substitutes and arbitrage risk also explain time-series variations in elasticities.

\author{
Jung-wook Kim \\ Department of Finance \\ University of Alberta \\ Edmonton Alberta \\ Canada T6G 2R6 \\ jungwook.kim@ualberta.ca \\ Jason Lee \\ Department of Finance \\ University of Alberta \\ Edmonton Alberta \\ Canada T6G 2R6 \\ jasonlee@ualberta.ca \\ Randall K. Morck \\ Department of Finance \\ University of Alberta \\ Edmonton Alberta \\ Canada T6G 2R6 \\ and NBER \\ randall.morck@ualberta.ca
}


In this paper, we use a unique dataset from the Korea Stock Exchange to examine the demand and supply schedules for common stocks. Our dataset allows us to identify limit orders submitted by three types of investors: domestic individuals, domestic institutions, and foreign investors. Using this feature, we investigate demand and supply elasticities across these three types of investors in general, and then study their changes around the 1997 Asian financial crisis. To the best of our knowledge, our paper is the first evidence that heterogeneous investors have differing demand and supply schedules and that the elasticities of different investor types are affected differently by a financial crisis.

The textbook description of arbitrage requires no capital and involves no risk. Arbitrageurs short an overvalued security and use the proceeds to buy its perfect substitute. In this environment, competition among arbitrageurs leads to perfectly elastic demand and supply curves for individual securities. However, in real stock markets, arbitrage does not work as effectively as the textbook description and the slopes of demand and supply curves are finitely elastic. ${ }^{1,2}$

Since Scholes (1972), the elasticities of demand and supply curves for common stocks have been a subject of extensive research. In the past, researchers have used two approaches to measuring these elasticities. One approach is to examine price changes associated with stock issues or repurchases. Another is to examine price changes of stocks added to market indexes. In this paper, we propose a third approach - the direct construction of demand and supply curves for individual stocks from detailed data on individual bids and offers in the course of normal daily trading in both call auction and continuous markets. ${ }^{3}$

We do this using a dataset which consists of over 550 million buy and sell orders submitted in the Korea Stock Exchange (KSE) for the period from December 1996 to December 2000. The methodology we develop using this data allows us to probe into the 
nature of demand and supply elasticity for stocks more deeply than previous studies in several ways.

First, by constructing daily demand and supply schedules for all common stocks listed in the KSE, we are able to directly estimate the daily elasticity measures of demand and supply curves in a general trading environment. Because the KSE opens with call auction and then switches to continuous trading, we estimate two measures of elasticity for both demand and supply curves. We find that for the opening auction, the average (median) elasticity of demand is $9.26(8.62)$ while it is $10.28(8.85)$ for the continuous trading hours. We also obtain comparable estimates for the elasticity of supply. Our estimates roughly fall in the middle of the spectrum of existing estimates based on the other two approaches.

Second, going beyond previous studies, our data let us investigate demand and supply schedules for different classes of investors. When we partition the sample by investor class, we find that both domestic institutions and foreign investors (mainly institutional investors) have substantially more elastic demand and supply schedules than domestic individual investors. This result indicates that institutional investors have more homogeneous expectations and are more responsive to changes in stock prices than are individual investors.

Third, and also beyond the scope of previous studies, we can examine how elasticities change. Since our sample period includes the 1997 Asian financial crisis, which led to sharp declines in stock prices in Korea and other countries in the region, we can examine the effect of this crisis on elasticities. We find that the crisis permanently reduced the demand and supply elasticities of both domestic individuals and domestic institutions, but had virtually no effect on the elasticities of foreign investors. Notably, demand and supply elasticities of domestic individual investors fall by almost 50\% from their pre-crisis levels. One possible explanation for this structural break can be found in an equally dramatic decrease in margin 
trading (over 90\% down from the pre-crisis level) which was exclusively used by domestic individuals before the crisis.

Finally, we relate time-series variation in our elasticity measures to variables related to time-series variation in information heterogeneity, differences in opinion among investors,

the availability of close substitutes, and resources for arbitrage. ${ }^{4}$ These variables include direct measures of information asymmetry among investors, intra-day volatility of returns, trading volume, and margin buying orders as a fraction of total buy orders submitted. These variables are highly significantly associated with our elasticity measures and explain a large proportion of time-series variations in elasticity.

The remainder of the paper is organized as follows. Section I contains a short overview of the relevant literature. Section II describes the data and elasticity estimation procedures. Section III discusses the estimated elasticity measures. In section IV, we discuss measures of information heterogeneity among investors and of resources for arbitrage. Regression results are provided in section V. Section VI concludes the paper.

\section{The Nature of the Demand and Supply Curves for Individual Securities}

The demand curve for ketchup describes how the quantity of ketchup consumers buy rises as the price of ketchup falls, all else equal. By all else equal, we typically mean no changes in the consumer's wealth, tastes, or information about the naturopathic benefits of a high-ketchup diet; or in the prices of complements and substitutes, like hot dogs and mustard. When any of these factors do change, we speak of a shift in the demand curve, rather than a movement along it.

In a famous satire, Summers (1985) likens asset pricing unto ketchup pricing. Pursuing this analogy, the demand curve for an individual stock describes how the quantity of shares investors demand rises as the price of the stock falls, all else equal. Again, all else 
equal means no changes in the investor's wealth, tastes (including time preference, risk aversion, and the like), or information about the fundamental value of the stock, or in the prices of substitutes, such as other stocks.

The elasticity of the demand curve for ketchup, like its position, depends on consumers' wealth, tastes, information, and the availability of close substitutes. The elasticity of the demand curve for a stock depends on the same factors.

Wealthier investors might react differently to a given change in the stock's price than would poorer investors. For example, if a stock's price falls to below what an investor perceives as its fundamental value, a wealthy investor buys heavily in the hopes of profiting when the price returns to its fundamental value. A poorer investor, if unable to borrow freely, cannot do this. Thus, all else equal, demand curves for stocks should be flatter if investors are wealthier.

Likewise, investors with different tastes react differently to the same price change. For example, more risk adverse or less patient investors might be less willing to buy very large amounts of a stock they believe to be slightly undervalued. Mitchell, Pulvino, and Staffford (2002) point out that arbitrage requires taking very large undiversified positions in a misvalued stock and holding those positions until the misvaluation is corrected. This requires both risk tolerance (for other things might happen to change the price before it corrects) and patience (for the correction might not occur promptly). Since greater investor risk aversion or less investor patience means that a given price decline induces less additional buying, they imply less elastic demand curves for individual stocks.

If different people have different information, or opinions, about the fundamental value of a stock (or the true worth of a high-ketchup diet), the demand curve becomes less elastic. This is because the range of possible equilibrium price becomes wider as the heterogeneity of investors' expectation increases. 
Heterogeneous information also determines the availability of close substitutes for any given stock. If an investor invests costly resources to gather and process information about a given stock and determines, say, that it is deeply undervalued, he naturally buys as much of the stock as he can - even by bidding at higher prices than the current equilibrium price. A small price increase does not induce him to stop buying the stock if it is still undervalued. Only a large price hike that raises the price to equal or exceed the investor's estimate of fundamental value can induce him to stop buying. This is because other stocks, which the investor has not spent resources valuing, are not perfect substitutes for this stock, which he knows to be deeply undervalued. An analogous story applies to supply curves. Thus, more heterogeneous information makes stocks more imperfect substitutes for each other, and consequently renders demand and supply curves for individual stocks more inelastic.

In fact, in a pure exchange framework, like the stock market, supply depends on the same factors as demand, for without production, technology-related variables and factor costs are irrelevant. Thus, the supply curve for an individual stock shifts with investors' wealth, tastes, and information, and with the prices of other stocks; and the same list of factors that determine the elasticity of demand also determine the elasticity of the supply curve. ${ }^{5}$

Thus, at a technical level, the demand or supply curves for stocks seem not much different from the demand or supply curves for ketchup in a pure exchange economy. However, the critical differences between ketchup pricing and asset pricing are the commonplace assumptions in the latter that:

1. At least some investors can borrow cash and stocks freely to buy under-valued stocks and short over-valued stocks without limit and are willing to do so. That is, some investors have infinitely deep pockets and no risk aversion, and thus can freely engage in unlimited arbitrage trading. 
2. There is no information heterogeneity. That is, all investors, except insiders, have the same estimate of the fundamental value of all stocks. Any deviation of the stock price from this value consequently leads to unlimited arbitrage trading, which quickly returns the price to its consensus value.

3. All stocks are priced at their fundamental values. The absence of information heterogeneity means that new information comes to all investors simultaneously. This makes shares simply claims to future cash flows with different degrees of risk. Consequently, every stock has numerous perfect substitutes - all other stocks and portfolios with the same level of risk. $^{6}$

These three interdependent assumptions render the demand and supply curves for individual stocks perfectly elastic, or horizontal. In other words, if any of the above assumptions is violated, the perfect elasticity of demand and supply curves is not guaranteed.

Scholes (1972) therefore stresses the importance of empirically verifying that the elasticities of demand and supply for individual stocks are very large. To this end, he examines secondary offerings, and concludes that the associated stock price declines are due to information conveyed by firms' decisions to issue shares, and do not imply inelastic investor demand or supply. Mikkelson and Partch (1985) reexamine secondary equity distributions and find variables they expect to be related to the elasticity of demand for stocks insignificant in explaining the price impact of secondary offerings. They consequently second Scholes' conclusion.

The first evidence for downward sloping demand curves is Shleifer (1986), who reports that a stock's price rises permanently upon its inclusion in the Standard and Poor's 500 index (S\&P 500). Shleifer argues that, because index funds must buy such a stock, its demand curve mechanically shifts to the right. If the demand curve were flat, this shift would 
have no price impact. Shleifer therefore interprets his finding of a large and permanent price rise as evidence of imperfectly elastic demand curves for individual stocks.

However, Harris and Gurel (1986) report that these price increases are temporary, and attribute them to temporary liquidity shortfalls associated with trading by index funds, rather than to downward sloping demand curves. Other studies, including Jain (1987), Dhillon and Johnson (1991), Beneish and Whaley (1996), and Lynch and Mendenhall (1997) fail to replicate this finding. Jain (1987) finds price increases in included firms' bonds, and Dhillon and Johnson (1991) find price increases for stocks included in indexes that are not tracked by index funds. Consequently, they argue that the permanent price rise noted by Shleifer (1986) may result from a certification effect: addition to an index conveys positive information about a company's future prospects. Furthermore, Denis et al. (2003) find that newly added firms to the S\&P 500 index experience significant increases both in earnings per share forecasts and in realized earnings. They interpret these results as supporting the view that S\&P 500 inclusion is not an information free event.

Nonetheless, other evidence regarding index demand supports Shleifer's (1986) conclusions. For example, Kaul et al. (2000) find permanent stock price changes associated with changes to the weights of firms in the Toronto Stock Exchange 300 Index. Since no stocks are added to the index, and the weight changes are both preannounced and purely mechanical, a certification effect can be ruled out. Wurgler and Zhuravskaya (2002) find that price reactions to inclusion into the $\mathrm{S} \& \mathrm{P} 500$ index are negatively related to the availability of close substitutes for included stocks. Since the lack of close substitutes hinders arbitrage activities, demand curves become more inelastic, resulting in large price impacts. Thus, the controversy is far from settled.

A second approach, assessing price elasticities using data from auctions, also favors finitely elastic demand and supply curves. Bagwell (1992) uses 32 Dutch auction stock 
repurchases to estimate price elasticities of supply curves for individual securities. She reports that repurchasing firms face upward-sloping supply curves for their shares, and that heterogeneity of valuations is the main cause for the shape of the supply curve. Similarly, Kandel et al. (1999), using 27 Israeli initial public offerings (IPOs), directly estimate downward sloping demand curves for individual stocks.

Moreover, studies that support the view that the demand and supply curves for common stocks are imperfectly elastic report differing elasticities. For example, the imputed elasticites of demand reported by Kaul et al. (2000) and Wurgler and Zhuravskaya (2002) are 10.50 and 7.87, respectively. In contrast, Bagwell (1992) reports a mean elasticity of 0.68; while Kandel et al. (1999) report a mean gross elasticity of 2.91 and a mean local elasticity of 37.10. It should be, however, noted that Dutch auction repurchases and IPOs represent special corporate events.

\section{Empirical Framework and Data}

\section{A. KSE Market Structure}

The KSE is an order-driven market. The trading session starts at 9:00 and closes at 15:00. ${ }^{7}$ Throughout the trading session, a trader may place either a limit order or a market order, which is directly transmitted to the KSE via the computerized order-routing system. The automated trading system of the exchange prioritizes each order by price and then by time. The KSE opens with a call market and then switches to a continuous market. In the opening auction, all bids and offers submitted are regarded as simultaneous and matched at a single price. ${ }^{8}$ Trading prices during the rest of trading hours are determined by continuous auction, whereby a new bid (offer) entered into the automated trading system is matched with any unfilled offers (bids). ${ }^{9}$ Like all other markets, the KSE has a minimum price increment (tick), which determines what prices traders use. The size of the tick varies substantially 
across stocks, depending on the price level. For example, a stock priced at 5000 won trades on 5 won increments while a stock priced at 50,000 won trades on 50 won increments. ${ }^{10}$

Market participants observe part of the limit order book. During our sample period, from December 1996 to December 2000, the KSE made order sizes for the five lowest sell and five highest buy prices available to the public. ${ }^{11}$ The availability of this information lets traders partially observe the demand and supply schedules of each stock before they submit their own orders.

\section{B. Data}

Our basic data are from the KSE's Trade and Quote (KSETAQ) records. We include all common stocks listed in the KSE between December 1996 and December 2000, a total of 49 months.

The KSETAQ database provides detailed information on each order placed and each trade executed. In addition to the price, order size, and time of arrival, this database contains detailed information regarding each order and each executed trade that is unavailable elsewhere. First, the database tags each order as either a buy or a sell, and further classifies each buy or sell order as a market or limit order. Second, it contains information about investor type. With this information, we are able to distinguish between three types of investors: (a) domestic individuals, (b) domestic institutions, and (c) foreign investors. Third, it has an indicator for a margin purchase or short sale order. Finally, the KSETAQ data distinguishes orders in the call market auctions held at the opening from orders in the continuous trading that occurs during the remainder of each day. The database provides this information on each order and on each trade executed. 
Given these data, we construct the demand and supply schedules for each stock at the opening auction and during the rest of the day. In addition, we examine differences in demand and supply schedules by investor type.

\section{Insert Table I about here}

Panels A and B of Table I summarize the distribution of the over 550 million orders submitted in the KSE during our sample period. These orders are partitioned into buy and sell orders, and then sorted by order type (market versus limit orders), investor type (domestic individuals, domestic institutions, and foreign investors), and trading session (opening call market auction versus continuous trading during the rest of trading hours). Most orders are limit orders (94.78 percents of buy orders and 92.99 percent of sell orders). In addition, individual investors dominate trading. Specifically, individual investors submit 95.70 percent of buy orders and 95.34 percent of sell orders; while domestic institutions and foreign investors collectively submit only 4.30 percent of buy orders and only 4.66 percent of sell orders. $^{12}$ However, individual investors' orders are much smaller than those of domestic institutions and foreign investors. Individual buy orders average only 1,217.09 shares, while those of domestic institutions average 3,568.22 shares and those of foreign investors average 1,909.20 shares. Finally, 19.10 percent of buy orders and 21.14 percent of sell orders were submitted to the opening session.

Panel C of Table I summarizes the distribution of our approximately 387 million trade records. As with orders, individual investors dominate actual transactions. Specifically, 90.05 percent of buyers and 89.69 percent of sellers are individual investors during our sample period. In contrast, domestic institutions and foreign investors collectively

participated in about 10 percent of transactions. This participation rate is actually 
surprisingly high, because, as Panels A and B show, these investors submit less than 5 percent of total orders during our sample period. Panel $\mathrm{C}$ of Table I shows that the average trades by domestic institutions and foreign investors are larger than those of individual investors. However, these average values may not reflect the actual differences in trade size across investor types because of the way orders map into transactions. For example, if an order is submitted and executed in parts over the course of the trading session, the single order gives rise to several executions. When this happens, the KSE reports each execution as a transaction. Thus, the average trade sizes reported in Panel $\mathrm{C}$ of Table I understate actual trade sizes.

\section{Insert Figure 1 about here}

Figure 1 shows the time-series of the Korea Composite Stock Price Index (KOSPI) during our sample period.

\section{Elasticity Measures of Demand and Supply}

In estimating the slopes of demand and supply curves, we use a modification of the approach of Bagwell (1992). Specifically, for the opening session and the rest of trading hours, we separately accumulate all limit orders submitted at or above (at or below) each price point to construct demand (supply) schedules. ${ }^{13}$ Then, all bid and ask prices are normalized such that the opening auction price (closing price) is 100 for demand and supply

schedules of the opening auction (rest of trading hours). ${ }^{14}$ We also normalize quantity to measure the cumulative percentage of total quantity demanded or supplied during each trading session. Bagwell (1992) shows that this normalization of both prices and quantities allows a linear regression on levels to generate estimates of elasticities directly. ${ }^{15}$

Thus, for each trading day, the elasticities of demand and supply are estimated by running the following regression: 


$$
p_{j k}=\alpha_{j}+\beta_{j} d_{j k}+\varepsilon_{j k}
$$

where $p_{j k}$ and $d_{j k}$ represent the normalized price and normalized market-wide cumulative quantity at tick point $k$ for firm $j$. At each normalized price level $p_{j k}$, we sum bids from all investors to obtain the market's demand for stock $j$. Thus,

$$
d_{j k}(p)=\sum_{i=1}^{I} \sum_{\pi \geq p} n_{i j k}(\pi)
$$

where $n_{i j k}(\pi)$ is the number of shares of stock $j$ for which investor $i$ bids price $\pi$ in buy orders valid on a given day. We use regression (1) to estimate the inverse of (2), so the corresponding elasticity is approximated by the absolute value of the inverse of the slope coefficient; that is, $\eta_{j}=\left|\beta_{j}^{-1}\right|$. We estimate (1) for each trading session, the opening call market and the continuous market operating for the rest of the day, for all stocks with at least five price-quantity pairs with nonzero quantities demanded. We then repeat this procedure using offers instead of bids to estimate supply elasticities. ${ }^{16}$ That is,

$$
s_{j k}(p)=\sum_{i=1}^{I} \sum_{\pi \leq p} m_{i j k}(\pi)
$$

where $m_{i j k}(\pi)$ is the number of shares of stock $j$ for which investor $i$ asks price $\pi$ in sell orders valid on a given trading day.

As shown in Table I, the number of orders submitted for the opening auction is substantially smaller than that for the rest of trading hours. This constrains our ability to estimate demand and supply elasticities by investor type for the opening auction. Consequently, we estimate the opening session slopes of demand and supply curves without considering different types of investors. For the rest of each day's trading hours, however, the elasticities of demand and supply are estimated separately for each investor type. ${ }^{17}$ 


\section{Elasticities of Demand and Supply}

Panel A of Table II reports summary statistics for daily average elasticity of demand curves. ${ }^{18}$ The R-squared values of regression (1) average 82.55 percent for the opening auction and 77.40 percent for the rest of trading hours. The mean (median) elasticity of demand is $9.26(8.62)$ for the opening auction and $10.28(8.85)$ for the rest of trading hours. This means demand for the average stock falls by $9.26 \%(10.28 \%)$ when its price rises by $1 \%$ during the opening auction (rest of trading hours). Panel B of Table II shows elasticities of supply to be of comparable magnitudes. Thus, we find that demand curves for individual stocks are downward sloping and supply curves for individual stocks are upward sloping.

\section{Insert Table II about here}

Our estimates of demand and supply elasticity roughly match the imputed elasticity of 10.50 in Kaul et al. (2000), and slightly exceed the 7.89 estimate obtained by Wurgler and Zhuravskaya (2002). However, our estimates greatly exceed the mean (median) elasticity of 0.68 (1.05) reported by Bagwell (1992) for Dutch auction share repurchases. Our elasticity estimates are also much larger than the mean (median) estimate of 2.91 (2.47) estimated by Kandel et al. (1999) using IPO price data. One possible explanation of the differences is that we measure elasticities in the course of normal trading, while Bagwell (1992) and Kandel et al. (1999) measure elasticity at special corporate events. Another possibility, mentioned earlier, is that investors in the KSE can observe the quantities demanded and supplied at the five best prices, whereas general investors elsewhere have much less information.

\section{A. Time-Series Patterns of Elasticity Measures}

Our sample period includes the 1997 Asian financial crisis, which led to substantial equity losses in Korea and other countries in the region. During the crisis period, many 
Korean investors lost considerable wealth. From September 1997 to December 1997, the Korean won fell by 54\% relative to the U.S. dollar - from 914.40 to 1695.00 won per dollar, while the Korea Composite Stock Price Index (KOSPI) dropped by almost $42 \%$ - from 647.11 to 376.31. Corporate bankruptcies and ensuing layoffs further eroded investor wealth. It also became more difficult for Koreans to borrow money (and presumably also to borrow stock for short sales). For example, the yield on 91-day commercial paper in Korea rose from $13.88 \%$ to $29.26 \%$ during the same 3 -month period. ${ }^{19}$ Certainly, changing time preferences and risk aversion plausibly explain part of this rise. Finally, it seems likely that investors acquired new information about Korean stocks through the crisis. It is clear that these large changes in investor wealth, tastes, and information shifted demand and supply curves for individual stocks downward, for stock prices fell. In this section, we explore whether elasticities of demand and supply also changed.

We therefore break the sample into three sub-periods: (a) the pre-crisis period (December 1996 - October 1997), (b) the in-crisis period (November 1997 - October 1998), and (c) the post-crisis period (November 1998 - December 2000).

\section{Insert Figures 2 and 3 about here}

Figures 2(a) and 2(b) plot the time-series of the daily average demand elasticities. ${ }^{20}$ They also show the number of firms used in calculating each of these values. Figure 2(a) shows that the demand elasticity for the opening auction varies substantially over the sample

period. Demand becomes markedly less elastic in the latter part of the sample period. ${ }^{21}$ The figure also highlights an obvious structural break following the Asian financial crisis. Summary statistics of elasticity measures for the three sub-periods are listed in Panel A of Table II. For the opening auction, the average demand elasticity is 13.27 in the pre-crisis 
period, but only 7.08 in the post-crisis period. Thus, the magnitude of demand elasticity falls $46 \%$ in absolute value with the crisis, and this difference in the elasticity (6.19) is significant at the one percent level. Figure 2(b) and Panel A of Table II show a similar pattern in demand elasticity for the rest of trading hours, and the decline is likewise highly significant.

Figures 3(a) and 3(b) exhibit the time-series patterns of supply elasticity and the numbers of firms used each trading day in estimating these elasticity measures, while Panel B of Table II presents summary statistics for the three sub-periods. Mimicking the pattern in demand elasticities, supply curves are significantly less elastic after the 1997 financial crisis.

\section{B. Opening-Auction Elasticity versus Rest-of-Day Elasticity}

All orders submitted during the opening auction are regarded by the KSE as simultaneous and are matched at a single price. Kalay et al. (2001) argue that auctions of this type provide a natural environment for investigating the demand and supply curves of individual common stocks because the confounding effects of new information are minimal. However, the smaller number of orders submitted to the opening auction constrains our ability to examine demand and supply elasticities by investor type. In contrast, the greater number of orders typically submitted during the rest of trading hours lets us compare elasticities for different classes of investors, but allows the criticism that demand and supply curves may shift as new information arrives. Thus, estimating elasticities using data for the rest of trading hours imposes a stationarity assumption, which may be inappropriate.

To investigate the appropriateness of the stationarity assumption, we partition the sample into quintiles on the basis of the percentage of orders cancelled or revised during each trading day. We take a large number of such revisions and cancellations as indicative of shifts in the demand or supply curves during a given day. Table III reports regressions of our opening elasticities on the elasticities for the rest of trading hours for each quintile. ${ }^{22}$ 


\section{Table III about here}

Panel A shows the two demand elasticity estimates to be highly significant, and the adjusted R-squared values to exceed 80 percent in all five sub-samples. Although the regression coefficient monotonically decreases with the percentage of cancelled or revised orders, the difference between the first and fifth quintile estimates is only about fifteen percent of their average magnitude. Thus, our results strongly suggest that the openingauction and rest-of-trading-hour elasticities measure the same underlying phenomenon. The results in Panel B show a similar pattern in the supply elasticity estimates. Overall, the results in Table III justify that the assumption of the within-day stationarity is a reasonable first approximation, but indicate grounds for some caution as well. ${ }^{23}$

\section{Investor Types and Time-Series Patterns of Elasticity}

Prior studies of demand and supply elasticities for individual securities (e.g., Bagwell (1992) and Kandel et al. (1999)) do not distinguish different types of investors. However, other research suggests possible systematic differences between different investor categories.

First, traders with higher quality information should probably be both more certain about fundamental securities values than less informed traders and more in agreement with each other. Thus, all else equal, more informed traders should have more elastic demand and supply curves for individual securities. Second, traders with deeper pockets should have more elastic demand and supply curves for individual stocks. This is because rapidly rising margin and short sale costs prevent traders without deep pockets from taking very large positions, even when they are very sure of their estimates of fundamental values. Therefore, to distinguish investors who might have different elasticities, we consider categories of 
investors who might have different quantities and qualities of information, and who might have pockets of differing depth.

One such categorization distinguishes institutional investors from individuals. Certainly, institutions have deeper pockets than all but the wealthiest individuals.

Also, much recent work suggests different information behind the trades of institutions and individuals. Lev (1988) argues that institutional investors have a lower marginal cost of gathering information and are generally better informed than individual investors. Kim and Verrecchia (1994) and Cohen et al. (2002) propose that institutional investors possess superior information processing ability. Shiller and Pound (1989) report that institutional and individual investors differ as to how they acquire information. Specifically, institutions typically do formal investment analyses and have access to costly databases. These considerations suggest that institutional orders and trades might be more homogeneous and carry more information than those by individuals.

However, Lakonishok et al. (1991, 1992) posit that institutional fund managers engage in a range of trading activities motivated by herding, window dressing, and the like. Scharfstein and Stein (1990) provide a theoretical framework where concerns for reputation generate herding driven by a 'share the blame' effect among managers. Dennis and Strickland (2002) find some evidence for herding by mutual and pension fund managers in the U.S. stock market. Herding might make institutional trading appear uninformed. Nonetheless, insitutional investors' opinions might still be homogeneous around prices where herding occurs. Determining whether individuals or institutions possess more information is beyond the scope of this paper, though we plan further work in this direction. Here, our concern is which sort of investor makes more homogeneous valuations.

Another categorization distinguishes domestic investors from foreign investors. The depth of domestic investors' pockets should vary with the health of the domestic economy. 
In contrast, the depth of foreigners' pockets should vary with the health of the world economy. Also, following Malaysian Prime Minister Mahathir Mohamad who famously blamed the Asian financial crisis of the 1990s on fad-driven foreign investors, much research has focused on whether foreign investors are more, less, or differently informed than domestic investors. Using Finish data, Grinblatt and Keloharju (2000) find foreign investors typically taking opposite trades to those of domestic institutional and individual investors. Seaholes (2000) presents evidence that foreign investors in Thailand and Taiwan also tend to trade against domestic institutional and individual investors. In contrast, Choe, Kho, and Stulz (1999) show that foreign investors in Korea behave much like domestic institutions but not individuals during the Asian financial crisis. Thus, the extent to which foreign investors behave differently from domestic investors is still incompletely understood, and which is better informed remains an open question.

Because the KSE database identifies trader type for each order submitted, it allows us to examine the behavior of different investor classes. Specifically, we break our sample of limit orders submitted during each day's continuous trading into three groups: (a) orders submitted by domestic individuals, (b) orders submitted by domestic institutions, (c) orders

submitted by foreign investors. ${ }^{24,25}$ Then, we estimate the elasticity of demand and supply for each investor class. This analysis provides a sense of how the supply and demand schedules of these investors differ and of how they change around the Asian financial crisis.

\section{Insert Table IV and Figure 4 about here}

Table IV presents summary statistics of daily average elasticity measures for each investor class. Panel A indicates that the elasticity of demand for common stocks differs substantially across different classes of investors. Individual investors have a mean (median) 
elasticity of 10.44 (8.96), which is significantly lower than the 18.90 (18.88) and 21.77 (21.46) estimates for domestic institutions and foreign investors, respectively. Because foreign investors in Korea are predominantly institutional investors, our findings suggest that institutional investors' demand is much more sensitive to price changes than is that of individual investors. Panel B of Table IV reports similar results for supply elasticities. These findings suggest that institutions as a group have more homogeneous valuations than individual investors have. Our findings also indicate that foreign investors' elasticities of demand and supply resemble those of domestic institutions, not those of individual investors. This is consistent with Choe, Kho, and Stulz (1999).

Figures 4(a) and 4(b) reveal that the elasticities of different classes of investors change differently over time. The demand and supply curves of individual investors become much less elastic following the 1997 crisis. In Panel A of Table IV, the mean elasticity of demand for domestic individual investors falls almost 50 percent (from 15.83 to 7.96 ), and this change is statistically significant at the one percent level. The mean elasticity of demand for domestic institutions simultaneously falls less - by 24 percent (from 22.63 to 17.17). However, the mean elasticity of demand for foreign investors hardly changes - from 22.00 in the pre-crisis period to 21.77 in the post-crisis period. Panel B shows that the elasticities of supply for these three categories of investors change in much the same ways.

Overall, Table IV and Figure 4 show intriguing differences in behavior among different classes of investors that have not been documented in the previous literature. We show that both domestic and foreign institutional investors have substantially more elastic demand and supply schedules than individual investors. This result implies that a small change in an individual stock's price results in a much larger change in institutional investors' demand and supply than in individual investors' demand and supply. We also show that the Asian financial crisis affected domestic and foreign investors differently. 
While it sharply reduced the demand and supply elasticities of domestic investors, it did not alter foreign investors behavior in any meaningful way.

\section{Insert Figure 5 about here}

Domestic institutions and foreign investors might mainly trade certain high profile firms, for example large firms. Thus, our results might be driven by a firm size effect or some other anomaly associated with a specific type of firm. ${ }^{26}$ To check this possibility, we repeat our empirical analysis using a restricted sample of firm-days that have elasticity measures for all three investor categories. However, Figure 5 shows that the time-series patterns for this restricted sample are similar to those in Figure 4.

\section{Potential Determinants of Time-Series Variations in Demand and Supply Elasticities}

Section III showed a structural break in the magnitude of demand and supply elasticities around the time of the Asian financial crisis. However, there is also substantial variation within each sub-period. This section considers factors that might underlie the timeseries variation in elasticities by constructing proxies for the time-series variation in information heterogeneity (or differences of opinion) and available resources for arbitrage. We then check how strongly the time-series variation of each proxy is correlated with the time-series variation of our demand and supply elasticities

First, we construct three proxies for the heterogeneity of investors' private information (and/or difference in opinion) about individual stocks. These are: (a) the asymmetric information component of bid-ask spreads, (b) intraday volatility, and (c) share turnover. Second, we use the ratio of margin buy orders to total buy orders submitted to 
proxy for the vigor of arbitrage activity. These variables derive from individual orders submitted (i.e., the asymmetric information component of the spread and the ratio of margin buy orders to total buy orders) or transactions executed (i.e., the intraday volatility and share turnover) for each firm each day. Finally, we calculate cross-sectional averages for each variable on each trading day to generate aggregated time-series variables. Detailed discussions of these variables are provided below.

\section{A. Adverse Selection Component the Bid-Ask Spread}

Information asymmetry models in the market microstructure literature assume two types of investors: informed traders and liquidity traders. Informed traders trade because they have private information, while liquidity traders trade for reasons other than superior information. Copeland and Galai (1983), Glosten and Milgrom (1985), and Easley and O’Hara (1987) suggest that liquidity traders sustain losses from trading with informed traders. Thus, the presence of informed traders increases information asymmetry among market participants, who consequently include an adverse selection cost in the bid-ask spread to cover their expected losses to informed traders.

The existence of privately informed traders can be measured by the magnitude of this adverse selection component of the bid-ask spread. As discussed in Kandel et al. (1999), greater asymmetry of information should induce less elastic demand curves. Thus, we expect demand curves to be more inelastic when the adverse selection component of the spread is higher. In addition, as bid-ask spreads increase, traders incur greater trading costs, further limiting arbitrage activities, and thereby rendering demand and supply curves even more inelastic.

To investigate the effect of private information heterogeneity on the elasticities of demand and supply, we decompose bid-ask spreads into realized half-spreads and adverse 
selection components using the method of Huang and Stoll (1996). The realized half-spread represents the post-trade revenues earned by liquidity providers while the adverse selection component reflects the amount lost by liquidity providers to informed traders. We define the spread as the difference between the prevailing lowest ask and highest bid prices. ${ }^{27}$ To estimate the realized-half spread, we first identify each trade as either buyer- or sellerinitiated. The realized half-spread for time horizon $\tau$ is

$$
\text { Realized Half }- \text { Spread }=\text { Trade }_{t+\tau}-\text { Trade }_{t}
$$

for a seller-initiated trade and

$$
\text { Realized Half }- \text { Spread }=-\left(\text { Trade }_{t+\tau}-\text { Trade }_{t}\right)
$$

for a buyer-initiated trade, where Trade $_{t}$ is the transaction price at time $t$ and $\operatorname{Trade}_{t+\tau}$ is the transaction price at $t+\tau$. In estimating realized half-spreads, we set $\tau$ equal to five minutes. ${ }^{28}$ The adverse selection component of the spread is then the difference between the bid-ask spread and the realized half-spread. Because the bid-ask spread is highly dependent on the tick size, which, in turn, depends on the price level, we use a relative measure of the spread: the bid-ask spread divided by the mid-point of the prevailing bid and ask prices.

\section{B. Intra-day Volatility}

French and Roll (1986) and Roll (1988) show that much of the variation in individual stock returns is firm-specific and unrelated to public announcements. Roll (1988) argues that stock price movements are therefore largely caused by investors trading on private firmspecific information. Higher volatility thus represents more active trading by informed arbitrageurs, and consequently, reflects a more heterogeneous distribution of private information across investors. Thus, periods of higher volatility should accompany periods of inelastic demand and supply curves. However, higher volatility, though due to informed

trading by one set of arbitrageurs, makes the stock appear riskier to other potential 
arbitrageurs. $^{29}$ Since arbitrageurs often hold less than fully diversified portfolios, higher volatility makes them reluctant to take large positions even if they believe the stock to be mispriced. This effect can be strong, especially if arbitrageurs have short horizons, as in Benartzi and Thaler (1995) or Shleifer and Vishny (1997).

We estimate the intraday volatility for each stock and each trading day as the standard deviation of 5-minute returns, which are measured using the mid points of bid and ask prices.

\section{Share Turnover}

Karpoff (1986) notes that trading occurs when investors disagree about fundamental values. This presumably happens when different investors have access to different private information, or simply have different opinions. Thus, trading volume arguably measures the heterogeneity of expectations among investors, and periods of high trading volume should also be periods of inelastic demand and supply curves.

On the other hand, large trading volume could represent extensive liquidity-driven trading by uninformed investors. In this case, periods with larger trading volume should also be periods of lower trading cost for arbitrageurs and thus of more elastic demand and supply curves. Which of these effects dominates is an empirical question.

We measure trading volume as the number of shares traded divided by the total number of outstanding shares.

\section{Margin Buying and Short Sales}

The KSE data used in this study allow us to identify each margin buying or short sale order placed. Hence, we can investigate how margin buying and short sale activities affect the elasticities of demand and supply. Specifically, we might consider the ratios of margin buying and short sale orders to total buy and sell orders placed, respectively, as possible 
proxies for the arbitrage activities of informed buyers (sellers) who affect supply (demand) elasticity. However, as discussed in the following section, short sales are quite rare - less than $0.5 \%$ of total sell orders. Thus, we focus on the effect of margin buying orders on elasticities.

Also, a caveat must be inserted at this point. Two types of investors might engage in margin trading: arbitrageurs and optimistic noise traders. Both sorts of margin traders should place buy orders around the current market price, and this should flatten the demand curve. ${ }^{30}$ Thus, even if we cannot identify the primary users of margin trading, ${ }^{31}$ increased margin trading should be associated with more elastic demand curves.

Analogous links connect margin trading and the elasticity of the supply curves of individual stocks. One such link is through arbitrage: observing increased demand at the current market price, potential sellers might infer that buyers possess private information and therefore adjust their own expectations accordingly. This would concentrate new sell orders around a new equilibrium price level, flattening the supply curve. A second such link derives from the market timing ability of buyers, which may play an important role in the KSE. As discussed above, the KSE released information on the quantities demanded (supplied) at the five highest (lowest) prices during our sample period. This means traders partially observe the demand and supply schedules of each stock before they make trading decisions. Thus, buyers (both arbitrageurs and irrationally optimistic investors) might prefer to place their orders where they observe the supply curve to be relatively flat.

Two important institutional issues affect margin buying during our sample period. First, during the Asian crisis, most KSE stocks fell sharply, and many investors failed to meet the margin requirements. To guard themselves against increased default risks, brokerage houses took various measures. In December 1997, the Korea Securities Finance Corporation stopped lending money to brokerage firms, which borrow it to extend credit to individual 
investors. $^{32}$ In addition, brokerage firms increased their collateral requirement from 140 percent to, on average, 174 percent and hiked their initial margin from 40 percent to 70 percent. ${ }^{33}$ These changes make it more difficult for traders to exploit arbitrage opportunities and raised the probability of arbitrageurs being forced to unwind their positions prematurely and thereby incur losses. Financial analysts in Korea suggest that these changes impeded arbitrage in the stock market. ${ }^{34}$ As will be discussed, we suspect that this policy change is partly responsible for the structural break that we observe in our elasticity measures.

Second, all of our short sale orders and $99.99 \%$ of our margin purchase orders are from individual investors. Thus, margin orders mainly either gauge arbitrage by individual investors or reflect the optimistic sentiment of individual investors. If this result carries across to other stock markets, margin trades may be a useful general proxy for trading by individuals - at least in the absence of institutional changes that alter the availability of margin financing.

\section{E. Time-series Patterns of Potential Determinants of Elasticity}

\section{Insert Table $\mathrm{V}$ and Figure 6 here}

Table $\mathrm{V}$ presents summary statistics of the potential determinants of elasticity listed above, while Figure 6 plots their time-series patterns. All values reported are based on crosssectional averages for each trading day.

The adverse selection cost of buy orders (AdvCost-Buy) and of sell orders (AdvCostSell) display similar time-series patterns. Both variables are substantially higher during the in-crisis period than either before or after it. They also move together, with a correlation coefficient of 0.935 . We can interpret the adverse selection variables as indicating that heterogeneity in the private information possessed by investors rose sharply during the crisis, and then fell back following it. 
Like adverse selection costs, intra-day volatility (Volat) increases in the in-crisis period and falls back, though not quite to its pre-crisis level, in the third period. Again, this suggests much more heterogeneous information during the crisis, but only somewhat more heterogeneous information following it.

In contrast, trading volume (Volume) rises after the crisis. However, this increase in post-crisis trading volume comes with greater volatility. The magnitude of standard deviation of post-crisis period is more than four times larger than that of pre-crisis period.

Margin buying and short selling fall off dramatically around the start of Asian financial crisis. As Table V suggests, margin trading was about $20 \%$ of total buy orders before the crisis, but decreases to a mere $1 \%$ after the crisis. On the other hand, short sales were never widely used in the KSE, constituting about $0.5 \%$ of total sell orders before the crisis and becoming almost negligible after it.

The time-series patterns of each variable are interesting per se, since they encapsulate the stock market's condition before, during, and after the crisis. As noted above, the structural break in elasticities cannot be explained by an increase in the asymmetric information cost portion of spreads or by an increase in intraday volatility after the crisis. This is because both variables revert to their pre-crisis level, while the elasticities do not. The upward trend in trading volume could partly be explained by declining transactions costs due to wider use of the internet and mobile phones for stock market investing. This story got some empirical support in our data since post-crisis standard deviation of trading volume is much larger than that of pre-crisis period. However, Table II shows that standard deviations of elasticities for the rest of the trading day actually decreased a lot (about $45 \%$ from the precrisis level) in our data. On the contrary, a dramatic change in the magnitude of margin trading does correspond to the structural break in the elasticity measures. The structural break is most eminent in demand and supply elasticities of domestic individuals and margin 
trading is exclusively used by domestic individuals before the crisis. Thus, the underlying the observed changes in demand and supply elasticities around the crisis appear limited to this change in margin interest along with the obvious decrease in the wealth of Korean investors due to the crisis, a possible increase in their risk aversion, and a possible increase in their perception of the risk in the stock market

\section{Regression Results}

Section III showed that the elasticities of demand and supply change substantially over our sample period. Section IV considered variables that might capture the heterogeneity of expectations among investors, and hence the potential for arbitrage. To investigate the effect of these variables on the elasticities of demand and supply, we estimate the following regressions:

Model 1: $\eta_{t}=b_{0}+b_{1}$ AdvCost $_{t}+b_{3}$ Volume $_{t}+b_{4}$ Mrg $_{t}+b_{5} t+\varepsilon_{t}$

and

Model 2: $\eta_{t}=b_{0}+b_{2}$ Volat $_{t}+b_{3}$ Volume $_{t}+b_{4}$ Mrg $_{t}+b_{5} t+v_{t}$

We include a time trend variable $t$ in the regressions to correct for possible time trends in variables. All variables other than the time trend variable are averaged across all firms each trading day to obtain daily aggregate measures. Then, they are transformed by adding one and taking natural logarithms. When the dependent variable is the elasticity of demand (supply), the adverse selection cost is calculated using buy (sell) orders only.

Several comments on the specification of our regression model are in order.

First, our regression specification is partly motivated by the fact that the correlation between demand and supply elasticities is surprisingly high, suggesting that common factors 
might affect both. The correlation between demand and supply elasticities for the opening auction is 0.82 while that of the rest of the day is 0.71 .

Second, in our sample period, the adverse selection cost measures (AdvCost) and intra-day volatility (Volat) are highly correlated. ${ }^{35}$ This is not surprising, for these variables both reflect the local price impact of trading. To mitigate any multicollinearity problem, we estimate Model 1 and Model 2 separately, instead of including both adverse selection cost and intra-day volatility as independent variables in a single regression model.

Third, our specification investigates the contemporaneous relationship between elasticities and each variable over our sample period. Thus we do not attempt to address causality between our variables. This is partly because our elasticity measures are aggregated to a daily level, and so cannot address causality relationships that are probably only detectable at the intraday level.

All t-statistics are adjusted for serial correlation and heteroskedasticity using the generalized method of moments (GMM) procedure of Newey and West (1987).

\section{Insert Table VI about here}

Panel A of Table VI provides results from the time-series regression of the elasticity of demand - both over the entire sample period and by sub-period. For the entire sample period, the estimated coefficients on all the independent variables are highly significant at the one percent level. The coefficient on $A d v \operatorname{Cost}$ is negative. Thus, as the extent of information heterogeneity increases among traders, their expectations diverge and the demand curve becomes less elastic. The intraday volatility (Volat) is also negatively related to the elasticity of demand. This is consistent with large price movements reflecting the capitalization of private information possessed by informed traders who act as first movers. 
The estimated Volume coefficient is also negative in both models, so higher volume corresponds to more inelastic demand and supply curves for individual stocks. Finally, the coefficient on $\mathrm{Mrg}$ is positive, implying that margin orders tend to cluster around a price level (most plausibly the market price), thus increasing the elasticity of the demand schedule.

The leftmost columns of Panel B of Table VI present analogous time-series regression results for the elasticity of supply for the entire sample period. The results are very similar to those of elasticity of demand. The only exception is that the coefficient on Volume in Model 2 is positive, but insignificant.

However, caution is warranted in interpreting the regression results over the entire sample period. The time-series plots of elasticity measures and their determinants shown in Figure 6 strongly suggest a structural break at the time of the financial crisis. We therefore re-estimate Model 1 and Model 2 by sub-period. Again, we use three sub-periods: the precrisis period of December 1996 to October 1997, the in-crisis period of November 1997 to October 1998, and the post-crisis period of November 1998 to December 2000.

The remaining columns of Panel A of Table VI describe time-series regressions of elasticity of demand by sub-period. The coefficients on AdvCost, Volat, and Volume have the same signs in each sub-period as in the entire sample, and almost all the coefficients remain significant at the one percent level. The main difference is that the estimated coefficient on Mrg, is insignificant in the pre-crisis period in Model 1.

The remaining columns of Panel B of Table VI report time-series regressions of elasticity of supply by sub-period. As with the results for the elasticity of demand, the coefficients are generally significant at the one percent level and have consistent signs across the three sub-periods. The only exception is the coefficient on Volume. This coefficient is negative and significant in the pre-crisis period for both Model 1 and Model 2, but is 
insignificant in both the in-crisis and post-crisis period (Model 1) or significantly positive, especially in the in-crisis period (Model 2).

As discussed in Section IV.C, trading volume has two conflicting linkages with elasticity. Trading volume rises if investors disagree more, implying a negative effect on elasticity. However, a rise in trading volume can also increase elasticity because arbitrage is easier in a deeper market. Our negative Volume coefficient may imply that the former effect dominates the latter in the pre-crisis period, while they wash or reverse in importance in the in-crisis and post-crisis periods. The positive coefficient in Model 2 is large and significant, especially during the crisis period. If investors were forced to sell shares during this period for liquidity reasons, volume might be positively associated with supply elasticity.

It is interesting to note that, even though the margin trading variable falls on average by over ninety percent from the first to the third period, its effects on demand and supply elasticities still remain positive and significant after the crisis.

\section{Conclusions}

Using over 550 million limit orders submitted in the Korea Stock Exchange (KSE), we investigate the demand and supply schedules for common stocks across heterogeneous investor types in general, and then study their changes around the 1997 Asian financial crisis. To the best of our knowledge, we provide the first evidence that different investor types have differing elasticities and that their demand and supply schedules are affected differently by a financial crisis.

We find that domestic institutions and foreign investors (mainly institutional investors) have substantially more elastic demand and supply curves than domestic individuals. This result implies that institutions and foreigners have more homogeneous beliefs than domestic individuals, and consequently have more price sensitive demand and 
supply schedules for common stocks. The proportion of ownership held by institutional investors has increased in almost every stock market during the last two decades. Although we do not address causality issues directly, our empirical findings raise the possibility that the increased presence of institutional investors increases the price elasticity of demand and supply for common stocks. However, whether homogeneity among institutional investors represents rational valuation of securities or reputation-driven herding remains unclear.

Our sample period includes the 1997 Asian financial crisis, which led to sharp declines in stock prices in many Asian countries. Partitioning the sample into pre-, in-, and post-crisis sub-periods, we present evidence that the crisis affected different sorts of investors differently. Specifically, domestic investors' demand and supply curves became dramatically less elastic following the crisis, while the crisis had virtually no effect on those of foreign investors. For example, both demand and supply elasticities of domestic individual reduce by almost $50 \%$ from the pre-crisis level. Sharp decreases in the elasticity measures for domestic investors after the crisis could be due to a reduction in their available resources for arbitrage caused by restrictions on margin trading and decreases in investors' wealth. This asymmetric result also demonstrates that, even if domestic investors are affected by a country-specific (or region-specific) shock, foreign investors, presumably because of greater diversification in their portfolios, can continue trading and help restore normalcy in the local stock market.

We also find that variables that capture a higher degree of heterogeneity among investors, the lack of close substitutes, and arbitrage risk are associated with more inelastic demand and supply curves. The adverse selection component of the bid-ask spread (which measures the impact of private information possessed by a subset of investors and/or the availability of close substitutes), intraday volatility (which reflects the heterogeneity of opinions among investors and/or arbitrage risk for less than fully diversified arbitrageurs) and trading volume are significantly negatively related with the magnitude of elasticities. 
In passing, we also note that margin trading is almost exclusively an activity of individual investors. Thus, margin trading might be a useful proxy for individual investor activity in markets that, unlike the Korean Stock Exchange, do not separate trades by the two classes of investors. 


\section{References}

Bagwell, Laurie S., 1992, Dutch auction repurchases: An analysis of shareholder heterogeneity, Journal of Finance 47, 71-105.

Baker, Malcolm and Serkan Savasoglu, 2002, Limited arbitrage in mergers and acquisitions, Journal of Financial Economics 64, 91-116.

Baker, Malcolm and Jeremy Stein, 2002, Market liquidity as a sentiment indicator, working paper, Harvard University.

Benartzi, Shlomo and Richard H. Thaler, 1995, Myopic loss aversion and the equity premium puzzle, Quarterly Journal of Economics 110, 73-92.

Beneish, Messod, and Robert Whaley, 1996, An anatomy of the "S\&P Game": The effects of changing the rules, Journal of Finance 51, 1909-1930.

Choe, Hyuk, Bong-Chan Kho, and René Stulz, 1999, Do foreign investors destabilize stock markets? The Korean experience in 1997, Journal of Financial Economics 54, 227 254.

Cohen, Randolph B., Paul A. Gompers, and Tuomo Vuolteenaho, 2002, Who underreacts to cash-flow news? Evidence from trading between individuals and institutions, Journal of Financial Economics, forthcoming.

Copeland, Thomas E. and Dan Galai, 1983, Information effects on the bid-ask spread, Journal of Finance 38, 1457-1469.

De Bondt, W. F. M. and Richard H. Thaler, 1985, Does the stock market overreact? Journal of Finance 40, 793-805.

Denis, Diane K., John J. Mcconnell, Alexei V. Ovtchinnikov and Yun Yu, 2003, S\&P 500 index additions and earnings expectations, Journal of Finance 58, 1821-1840.

Dennis, Patrick J. and Deon Strickland, 2002, Who blinks in volatile markets, individuals or institutions? Journal of Finance 57, 1923-1949. 
Dhillon, Upinder, and Herb Johnson, 1991, Changes in the Standard and Poor's 500 list, Journal of Business 64, 75-85.

Easley, David and Maureen O’Hara, 1987, Price, trade size, and information in securities markets, Journal of Financial Economics 19, 69-90.

French, Kenneth R. and Richard Roll, 1986, Stock return variances: the arrival of information and the reaction of traders, Journal of Financial Economics 17, 5-26.

Glosten, Lawrence, and Paul Milgrom, 1985, Bid, ask, and transaction prices in a specialist market with heterogeneously informed traders, Journal of Financial Economics 13, $71-100$.

Grinblatt, Mark and Matti Keloharju, 2000, The investment behavior and performance of various investor-types: A study of Finland's unique data set, Journal of Financial Economics 55, 43-67.

Grossman, Sanford and Joseph Stiglitz. 1980, On the impossibility of informationally efficient markets, American Economic Review 70, 393-411.

Harris, Lawrance and Eitan Gurel, 1986, Price and volume effects associated with changes in the S\&P 500: New evidence for the existence of price pressures, Journal of Finance $41,815-829$.

Huang, Roger, and Hans Stoll, 1996, Dealer versus auction markets: A paired comparison of execution costs on NASDAQ and the NYSE, Journal of Financial Economics 41, 313-357.

Jain, Prem, 1987, The effect of stock price of inclusion in or exclusion from the S\&P 500, Financial Analysts Journal 43, 58-65.

Kalay, Avner, Orly Sade, and Avi Wohl, 2001, Measuring stock illiquidity: An investigation of the demand and supply schedules at the TASE, working paper, Tel-Aviv University and The University of Utah. 
Kandel, Shmuel, Oded Sarig, and Avi Wohl, 1999, The demand for stocks: An analysis of IPO auctions, Review of Financial Studies 12, 227-247.

Karpoff, Jonathan M., 1986, A theory of trading volume, Journal of Finance 41, 1069-1088.

Kaul, Aditya, Vikas Mehrotra, and Randall Morck, 2000, Demand curves for stocks do slope down: New evidence from an index weights adjustment, Journal of Finance 55, 893912.

Kim, Oliver and Robert E. Verrecchia, 1994, Market liquidity and volume around earnings announcements, Journal of Accounting and Economics 17, 41-67.

Lakonishok, Josef, Andrei Shleifer, Richard Thaler, and Robert Vishny. 1991. Window dressing by pension fund managers, American Economic Review 81, 227-32.

Lakonishok, Josef, Andrei Shleifer, and Robert Vishny. 1992. The structure and performance of the money management industry, Brookings Papers on Economic Activity 1992, $339-92$.

Lev, Baruch, 1988, Toward a theory of equitable and efficient accounting policy, The Accounting Review 63, 1-22.

Loderer, Claudio, John W. Cooney, and Leonard D. Van Druen, 1991, The price elasticity of demand for common stock, Journal of Finance 46, 621-650.

Lynch, Anthony, and Richard Mendenhall, 1997, New evidence on stock price effects associated with changes in the S\&P 500 Index, Journal of Business 70, 351-383.

Mikkelson, Wayne H. and M. Megan Partch, 1985, Stock price effects and costs of secondary distributions, Journal of Financial Economics 14, 165-194.

Mitchell, Mark, Todd Pulvino, and Erik Stafford, 2002, Limited arbitrage in equity markets, Journal of Finance 57, 551-584. 
Newey, Whitney K. and Kenneth D. West, 1987, A simple, positive semi-definite, heteroskedasticity and autocorrelation consistent covariance matrix, Econometrica 55, 703-708.

Roll, Richard. 1988, R², Journal of Finance 43, 541-566.

Scharfstein, David S., and Jeremy C. Stein, 1990, Herd Behavior and investment, American Economic Review 80, 465-479.

Scholes, Myron, 1972, The market for securities: Substitution versus price pressure and the effects of information on share price, Journal of Business 45, 179-211.

Sesaholes, Mark S., 2000, Smart foreign traders in emerging markets, working paper, Harvard Business School.

Shiller, Robert J., 2002, From efficient market theory to behavioral finance, Journal of Economic Perspectives, forthcoming.

Shiller, Robert J. and John Pound, 1989, Survey evidence on diffusion of interest and information among investors, Journal of Economic Behavior and Organization 12, 47-66.

Shleifer, Andrei, 1986, Do demand curves fro stock slope down? Journal of Finance 41, 579590.

Shleifer, Andrei and Robert W. Vishny, 1997, The limits of arbitrage, Journal of Finance 52, $35-55$.

Summers, Lawrence. 1985. On Economics and Finance. Journal of Finance 40, 633-5.

Wurgler, Jeffrey and Katia Zhuravskaya, 2002, Does arbitrage flatten demand curves for stocks?, Journal of Business 75, 583-608. 


\section{Footnotes}

${ }^{1}$ Shleifer and Vishny (1997) and Shiller (2002) suggest various reasons as to why arbitrage may not work as effectively as the textbook description.

${ }^{2}$ See Loderer, Cooney, and Van Drunen (1991) for detailed discussions on why demand and supply curves are finitely elastic in real stock markets.

${ }^{3}$ Kalay et al. (2001) also directly measure demand and supply elasticities for common stocks listed on the Tel Aviv Stock Exchange. However, they do not examine differences in elasticities across different investor types or changes in elasticities over time.

${ }^{4} \mathrm{We}$ are investigating the cross-sectional and intraday patterns of demand and supply elasticities in another paper.

${ }^{5}$ The above example shows the possibility of the existence of common factors that affect both demand and supply elasticities in the same direction in a pure exchange economy. This partly motivates our regression specification in section $\mathrm{V}$.

${ }^{6}$ This is strictly true of classical portfolio theory. Other treatments of asset pricing, such as Grossman and Stiglitz (1980), allow finitely elastic demand curves.

${ }^{7}$ Before May 19, 2000, the KSE held two trading sessions: a morning session (from 9:00 through 12:00) and an afternoon session (from 13:00 through 15:00).

${ }^{8}$ Orders not filled completely during the opening auction are passed on to the continuous auction unless they are cancelled or revised.

${ }^{9}$ During the last 10 minutes of the day, no trades and orders are collected for the closing batch auction at 15:00. For a more complete description of the KSE market structure, see Choe, Kho, and Stulz (1999).

${ }^{10}$ Complete information on minimum price variation is available on the KSE website (http://www.kse.org.kr). 
${ }^{11}$ Starting January 2001, traders observe order quantities for the ten lowest sell and ten highest buy prices.

${ }^{12}$ Trading by domestic institutions and foreign investors is concentrated on large companies. For example, almost 13 percent of buy and sell orders for Samsung Electronics, the largest company in Korea, are by these investors. Their orders account for almost 55 percent of quantities demanded and 49 percent of quantities supplied. They account for about 53 percent of Samsung shares traded.

${ }^{13}$ In estimating the elasticity of demand and supply, we use limit orders only because market orders, by definition, do not specify prices.

${ }^{14}$ We have repeated the empirical analysis normalizing demand and supply schedules of the rest of trading hours by the opening auction price. This alternative specification does not change our results.

${ }^{15}$ Regressions of logarithms of raw prices on those of raw quantities generate similar patterns to those shown in the tables, as described in footnote 18 .

16 The average number of price-quantity points for opening auction demand (supply) schedules is 19 (19). The average number for the rest of the day demand (supply) schedules is $26(27)$.

${ }^{17}$ For the rest of trading hours, we implicitly assume that the demand and supply curves are stable within a trading day. In Section III.B, we empirically investigate the validity of this stationarity assumption.

${ }^{18}$ As a robustness check, we estimate elasticities using the alternative regression specification $\log \left(q_{j k}\right)=\delta_{j}+\chi_{j} \log \left(p_{j k}\right)+\varepsilon_{j k}$, where $p_{j k}$ is the price corresponding to tick point $k, q_{j k}$ is the market-wide cumulative quantity demanded (supplied) at or above (at or below) the tick point $k$, and the absolute value of $\chi_{j}$ is the elasticity of demand (supply) for firm $j$ on a given 
trading day. The estimated elasticities from this approach are highly correlated with those described in the Tables. The correlation coefficients of the estimated elasticities are 0.775 for opening session demand and 0.768 for opening session supply. In addition, the pattern of signs and significance levels in all our results are preserved when we use these alternate elasticity measures. Consequently, we report the results based on the modified Bagwell approach in the paper.

${ }^{19}$ In addition, it became extremely difficult to buy on margin after the crisis, which further limited the amount of available money for stock investing. We look closely at changes in margin buying practices around the crisis in section IV.D.

${ }^{20}$ As discussed in Section II.C, we estimate the elasticity for each firm-day only if there are at least five different price points with non-zero quantities demanded. Figures 1(a) and 1(b) suggest that the numbers of firms satisfying this requirement are generally stable over the sample period. A sharp decline in the number of firms is evident in a brief window during the crisis.

${ }^{21}$ The time series of median values of elasticity closely resembles that of the means. Repeating our empirical analyses using median elasticities generates similar patterns of signs and statistical significance.

${ }^{22}$ We have repeated our analysis using individual firm-day elasticity measures instead of the daily average values. Although this approach reduces the adjusted R-squared values, overall inferences of the regressions are similar to those in Table III.

${ }^{23}$ In addition to the percentage of orders cancelled or revised, other variables such as the absolute price change from the opening to the closing of the market, trading volume, and intraday volatility may serve as indicative of shifts in the demand or supply curves during a given day. Repeating the analysis in Section III.B using these variables generates empirical results qualitatively similar to those reported in Table III. 
${ }^{24}$ The number of orders submitted during the opening auction is substantially smaller than that for the rest of trading hours. Especially, domestic institution and foreign investors rarely place orders in the opening auction. This constrains our ability to estimate elasticity measures by investor type for the opening auction.

${ }^{25}$ Foreign investors in Korea are mainly institutional investors such as mutual funds and pension funds.

${ }^{26}$ We find that demand and supply curves are more elastic for large firms than they are for small firms. During our sample period, the mean value of demand elasticities (supply elasticities) is 10.97 (9.90) for firms in the $5^{\text {th }}$ size quintile for the rest of trading hours while it is $8.78(8.17)$ for firms in the $1^{\text {st }}$ size quintile.

${ }^{27}$ In an order-driven market, it is not possible to place a buy (sell) order above (below) the prevailing lowest ask (highest bid) price. As a result, the effective spread is always the same as the quoted spread.

${ }^{28}$ We have repeated the empirical analysis using $\tau=30$ minutes. This does not affect our results in any meaningful way.

${ }^{29}$ Mitchell et al. (2002) and Baker and Savasoglu (2002) find that idiosyncratic risk is responsible for limited arbitrage.

${ }^{30}$ Baker and Stein (2002) develop a model where high liquidity (elastic demand and supply curves) is a symptom of a predominance of irrationally optimistic investors.

${ }^{31}$ If margin trading is mainly used by rational arbitrageurs, the market price converges to the fundamental value of the firm. On the contrary, if margin trading is used by noise traders with an optimism bias, the market price could end up higher than the true value of the firm - a bubble. In the former case, we ought not to observe a price reversal, while in the latter case we should observe an eventual price reversal. However, as De Bondt and Thaler (1985) 
show, the price reversal may happen quite gradually. This fact limits our ability to distinguish the two hypotheses - especially given the financial crisis and stock price collapse in the middle of our sample period.

32 The Korea Securities Finance Corporation, established in October 1955, is the sole provider of securities finance services in Korea under the Securities and Exchange Act.

${ }^{33}$ According to an article in Munhwa Ilbo (March 4, 1998), some brokerage firms increased their collateral requirements to 200 percent or more. Ssang Yong Securities Company, for example, increased its requirement to 250 percent.

${ }^{34}$ Munhwa Ilbo (March 4, 1998).

${ }^{35}$ For our sample, the correlation coefficient between $A d v$ Cost-Buy and Volat is 0.739 while it is 0.675 between AdvCost-Sell and Volat. 


\section{Table I}

\section{Distribution of Orders and Trades}

This table reports the distribution of orders submitted and trades executed in the Korea Stock Exchange (KSE) during the period December 1996 - December 2000. Buy and sell orders are partitioned into market and limit orders. Investors are classified as domestic individual investors, domestic institutional investors, and foreign investors. Each daily trading session is partitioned into the opening call market auction and the continuous trading during the rest of trading hours. Values in parentheses are average order sizes in shares in Panels A and B, and average trade sizes in Panel C.

Panel A: Distribution of Buy Orders Submitted

\begin{tabular}{|c|c|c|c|c|}
\hline Investor Type & Order Type & $\begin{array}{c}\text { Opening } \\
\text { Call Market }\end{array}$ & $\begin{array}{c}\text { Rest of Day } \\
\text { Continuous } \\
\text { Market }\end{array}$ & Entire Day \\
\hline \multirow{3}{*}{$\begin{array}{l}\text { Domestic } \\
\text { Individual }\end{array}$} & Market & $\begin{array}{c}3,462,466 \\
(1,054.44)\end{array}$ & $\begin{array}{c}8,678,562 \\
(1,221.05)\end{array}$ & $\begin{array}{c}12,141,208 \\
(1,173.54)\end{array}$ \\
\hline & Limit & $\begin{array}{c}46,596,656 \\
(1,169.03)\end{array}$ & $\begin{array}{c}197,009,332 \\
(1,231.02)\end{array}$ & $\begin{array}{c}243,605,988 \\
(1,218.26)\end{array}$ \\
\hline & Total & $\begin{array}{c}50,059,122 \\
(1,161.57)\end{array}$ & $\begin{array}{c}205,687,894 \\
(1,230.60)\end{array}$ & $\begin{array}{c}255,747,016 \\
(1,217.09)\end{array}$ \\
\hline \multirow{3}{*}{$\begin{array}{l}\text { Domestic } \\
\text { Institutional }\end{array}$} & Market & $\begin{array}{c}104,187 \\
(1,777.17)\end{array}$ & $\begin{array}{c}1,113,798 \\
(1,038.34)\end{array}$ & $\begin{array}{c}1,217,985 \\
(1,101.54)\end{array}$ \\
\hline & Limit & $\begin{array}{c}585,118 \\
(6,862.06)\end{array}$ & $\begin{array}{l}5,598,581 \\
(3,760.60)\end{array}$ & $\begin{array}{r}6,183,699 \\
(4,054.07)\end{array}$ \\
\hline & Total & $\begin{array}{c}689,305 \\
(6,093.49)\end{array}$ & $\begin{array}{l}6,712,379 \\
(3,308.89)\end{array}$ & $\begin{array}{l}7,401,684 \\
(3,568.22)\end{array}$ \\
\hline \multirow{3}{*}{ Foreign } & Market & $\begin{array}{c}53,474 \\
(2,468.17)\end{array}$ & $\begin{array}{c}526,211 \\
(1,331.09)\end{array}$ & $\begin{array}{c}579,685 \\
(1,435.98)\end{array}$ \\
\hline & Limit & $\begin{array}{c}246,740 \\
(3,361.41)\end{array}$ & $\begin{array}{c}3,317,035 \\
(1,883.88)\end{array}$ & $\begin{array}{r}3,563,775 \\
(1,986.18)\end{array}$ \\
\hline & Total & $\begin{array}{c}300,214 \\
(3,202.30)\end{array}$ & $\begin{array}{l}3,843,246 \\
(1,808.19)\end{array}$ & $\begin{array}{l}4,143,460 \\
(1,909.20)\end{array}$ \\
\hline \multirow{3}{*}{ All } & Market & $\begin{array}{c}3,620,127 \\
(1,096.11)\end{array}$ & $\begin{array}{c}10,318,122 \\
(1,205.92)\end{array}$ & $\begin{array}{c}13,938,249 \\
(1,177.40)\end{array}$ \\
\hline & Limit & $\begin{array}{c}47,428,384 \\
(1,251.10)\end{array}$ & $\begin{array}{c}205,873,390 \\
(1,309.54)\end{array}$ & $\begin{array}{c}253,301,774 \\
(1,298.60)\end{array}$ \\
\hline & Total & $\begin{array}{c}51,048,511 \\
(1,240.11)\end{array}$ & $\begin{array}{c}216,191,512 \\
(1,304.60)\end{array}$ & $\begin{array}{c}267,240,023 \\
(1,292.28)\end{array}$ \\
\hline
\end{tabular}


Panel B: Distribution of Sell Orders Submitted

\begin{tabular}{|c|c|c|c|c|}
\hline Investor Type & Order Type & $\begin{array}{c}\text { Opening } \\
\text { Call Market }\end{array}$ & $\begin{array}{c}\text { Rest of Day } \\
\text { Continuous } \\
\text { Market }\end{array}$ & Entire Day \\
\hline \multirow{3}{*}{$\begin{array}{l}\text { Domestic } \\
\text { Individual }\end{array}$} & Market & $\begin{array}{c}6,732,424 \\
(606.50)\end{array}$ & $\begin{array}{c}11,173,446 \\
(746.62)\end{array}$ & $\begin{array}{c}17,905,870 \\
(693.94)\end{array}$ \\
\hline & Limit & $\begin{array}{l}51,422,932 \\
(1,153.35)\end{array}$ & $\begin{array}{c}201,169,307 \\
(1,766.00)\end{array}$ & $\begin{array}{c}252,592,239 \\
(1,641.28)\end{array}$ \\
\hline & Total & $\begin{array}{c}58,155,356 \\
(1,090.05)\end{array}$ & $\begin{array}{c}212,342,753 \\
(1,712.36)\end{array}$ & $\begin{array}{c}270,498,109 \\
(1,578.56)\end{array}$ \\
\hline \multirow{3}{*}{$\begin{array}{l}\text { Domestic } \\
\text { Institutional }\end{array}$} & Market & $\begin{array}{c}190,256 \\
(1,142.47)\end{array}$ & $\begin{array}{c}1,329,346 \\
(762.77)\end{array}$ & $\begin{array}{c}1,519,602 \\
(810.31)\end{array}$ \\
\hline & Limit & $\begin{array}{c}985,626 \\
(6,433.11)\end{array}$ & $\begin{array}{c}6,411,346 \\
(4,199.12)\end{array}$ & $\begin{array}{c}7,396,972 \\
(4,496.80)\end{array}$ \\
\hline & Total & $\begin{array}{l}1,175,882 \\
(5,577.09)\end{array}$ & $\begin{array}{l}7,740,692 \\
(3,608.98)\end{array}$ & $\begin{array}{l}8,916,574 \\
(3,868.53)\end{array}$ \\
\hline \multirow{3}{*}{ Foreign } & Market & $\begin{array}{c}43,388 \\
(1,948.78)\end{array}$ & $\begin{array}{c}413,493 \\
(1,262.65)\end{array}$ & $\begin{array}{c}456,881 \\
(1,327.81)\end{array}$ \\
\hline & Limit & $\begin{array}{c}216,188 \\
(3,714.74)\end{array}$ & $\begin{array}{c}3,400,153 \\
(2,380.34)\end{array}$ & $\begin{array}{l}3,616,341 \\
(2,460.11)\end{array}$ \\
\hline & Total & $\begin{array}{c}259,576 \\
(3,419.56)\end{array}$ & $\begin{array}{l}3,813,646 \\
(2,259.16)\end{array}$ & $\begin{array}{l}4,073,222 \\
(2,333.10)\end{array}$ \\
\hline \multirow{3}{*}{ All } & Market & $\begin{array}{c}6,966,032 \\
(628.91)\end{array}$ & $\begin{array}{c}12,914,374 \\
(764.04)\end{array}$ & $\begin{array}{c}19,880,406 \\
(716.69)\end{array}$ \\
\hline & Limit & $\begin{array}{c}53,011,848 \\
(1,254.08)\end{array}$ & $\begin{array}{c}210,819,707 \\
(1,849.31)\end{array}$ & $\begin{array}{c}263,831,555 \\
(1,729.71)\end{array}$ \\
\hline & Total & $\begin{array}{c}59,977,880 \\
(1,181.47)\end{array}$ & $\begin{array}{c}223,734,081 \\
(1,786.66)\end{array}$ & $\begin{array}{c}283,711,961 \\
(1,658.72)\end{array}$ \\
\hline
\end{tabular}


Panel C: Distribution of Trade Records

\begin{tabular}{|c|c|c|c|c|}
\hline Investor Type & Order Direction & $\begin{array}{c}\text { Opening } \\
\text { Call Market }\end{array}$ & $\begin{array}{l}\text { Rest of Day } \\
\text { Continuous } \\
\text { Market }\end{array}$ & Entire Day \\
\hline \multirow{2}{*}{$\begin{array}{l}\text { Domestic } \\
\text { Individual }\end{array}$} & Buy & $\begin{array}{c}14,774,259 \\
(374.78)\end{array}$ & $\begin{array}{c}335,213,043 \\
(442.93)\end{array}$ & $\begin{array}{c}349,987,302 \\
(440.05)\end{array}$ \\
\hline & Sell & $\begin{array}{c}14,677,872 \\
(372.70)\end{array}$ & $\begin{array}{c}332,549,722 \\
(440.33)\end{array}$ & $\begin{array}{c}347,227,594 \\
(437.47)\end{array}$ \\
\hline \multirow{2}{*}{$\begin{array}{l}\text { Domestic } \\
\text { Institutional }\end{array}$} & Buy & $\begin{array}{l}440,944 \\
(804.29)\end{array}$ & $\begin{array}{c}25,256,326 \\
(616.26)\end{array}$ & $\begin{array}{c}25,697,320 \\
(619.49)\end{array}$ \\
\hline & Sell & $\begin{array}{l}645,917 \\
(711.19)\end{array}$ & $\begin{array}{c}28,185,855 \\
(624.28)\end{array}$ & $\begin{array}{c}28,831,772 \\
(626.22)\end{array}$ \\
\hline \multirow{2}{*}{ Foreign } & Buy & $\begin{array}{l}399,194 \\
(513.00)\end{array}$ & $\begin{array}{c}11,036,713 \\
(484.25)\end{array}$ & $\begin{array}{c}11,435,907 \\
(485.25)\end{array}$ \\
\hline & Sell & $\begin{array}{l}290,658 \\
(574.70)\end{array}$ & $\begin{array}{c}10,770,505 \\
(497.39)\end{array}$ & $\begin{array}{c}11,061,163 \\
(499.42)\end{array}$ \\
\hline \multirow{2}{*}{ All } & Buy & $\begin{array}{c}15,614,447 \\
(390.43)\end{array}$ & $\begin{array}{c}371,506,082 \\
(455.93)\end{array}$ & $\begin{array}{c}387,120,529 \\
(453.29)\end{array}$ \\
\hline & Sell & $\begin{array}{c}15,614,447 \\
(390.43)\end{array}$ & $\begin{array}{c}371,506,082 \\
(455.93)\end{array}$ & $\begin{array}{c}387,120,529 \\
(453.29)\end{array}$ \\
\hline
\end{tabular}




\section{Table II \\ Elasticity of Demand and Supply}

This table reports the elasticity of demand and supply during the period December 1996 - December 2000. Each trading day is partitioned into two sessions: opening auction and rest of trading hours. For each firm and each trading session, the daily elasticity is estimated using the following regression: $p_{j k}=\alpha_{j}+\beta_{j} d_{j k}+\varepsilon_{j k}$; where $p_{j k}$ and $d_{j k}$ represent the normalized price and normalized market-wide cumulative quantity at tick point $k$ for firm $j$ on a given trading day. The daily elasticity is defined as the inverse of slope coefficient (i.e., $\left.\eta_{j}=1 /\left|\beta_{j}\right|\right)$. Then, the daily elasticity measures are averaged across all firms. The sample period is divided into three sub-periods: (a) pre-crisis period (December 1996 - October 1997), (b) in-crisis period (November 1997 - October 1998), and (c) post-crisis period (November 1998 - December 2000).

\begin{tabular}{|c|c|c|c|c|c|}
\hline \multicolumn{6}{|c|}{ Panel A: Elasticity of Demand } \\
\hline Trading Session & Sub-Period & $\mathrm{N}$ & Mean & Median & Std. Dev. \\
\hline \multirow[t]{4}{*}{ Opening auction } & Entire sample period & 1,090 & 9.26 & 8.62 & 2.79 \\
\hline & Pre-crisis period & 265 & 13.27 & 13.30 & 0.70 \\
\hline & In-crisis period & 293 & 9.58 & 9.23 & 1.81 \\
\hline & Post-crisis period & 532 & 7.08 & 6.91 & 0.99 \\
\hline \multirow[t]{4}{*}{ Rest of trading hours } & Entire sample period & 1,090 & 10.28 & 8.85 & 3.50 \\
\hline & Pre-crisis period & 265 & 15.52 & 15.58 & 1.73 \\
\hline & In-crisis period & 293 & 9.91 & 9.64 & 2.38 \\
\hline & Post-crisis period & 532 & 7.86 & 7.80 & 0.95 \\
\hline \multicolumn{6}{|c|}{ Panel B: Elasticity of Supply } \\
\hline Trading Session & Sub-Period & $\mathrm{N}$ & Mean & Median & Std. Dev. \\
\hline \multirow[t]{4}{*}{ Opening auction } & Entire sample period & 1,090 & 9.06 & 8.36 & 3.02 \\
\hline & Pre-crisis period & 265 & 13.30 & 13.61 & 1.08 \\
\hline & In-crisis period & 293 & 9.62 & 9.21 & 1.98 \\
\hline & Post-crisis period & 532 & 6.64 & 6.44 & 0.96 \\
\hline \multirow[t]{4}{*}{ Rest of trading hours } & Entire sample period & 1,090 & 9.30 & 8.06 & 3.02 \\
\hline & Pre-crisis period & 265 & 13.56 & 13.80 & 1.63 \\
\hline & In-crisis period & 293 & 9.09 & 8.64 & 2.50 \\
\hline & Post-crisis period & 532 & 7.30 & 7.23 & 0.90 \\
\hline
\end{tabular}




\section{Table III}

\section{Proportion of Cancelled/Revised Orders and Potential Shifts in Demand and Supply Curves}

For each trading day, we divide the sample into five quintiles based on the portion of orders that are either cancelled or revised. Quintile 1 (Quintile 5) includes observations for which this proportion is the smallest (largest). Then, the elasticity for the opening auction is regressed on the elasticity for the rest of trading hours using the daily average elasticity measures. Values in parentheses represent tstatistics which are adjusted for serial correlation and heteroskedasticity using the generalized method of moments (GMM) with the Newey-West (1989) procedure.

\begin{tabular}{|c|c|c|c|c|}
\hline \multicolumn{5}{|c|}{ Panel A: Elasticity of Demand } \\
\hline & Intercept & Slope Coefficient & Adj. $R^{2}$ & $\begin{array}{c}\text { Mean Value of } \\
\text { Cancelled/Revised } \\
\text { Proportions }\end{array}$ \\
\hline Quintile 1 (smallest) & $\begin{array}{l}0.018 \\
(0.26)\end{array}$ & $\begin{array}{c}1.054 \\
(33.82)\end{array}$ & $82.07 \%$ & $12.08 \%$ \\
\hline Quintile 2 & $\begin{array}{l}0.055 \\
(1.16)\end{array}$ & $\begin{array}{c}1.026 \\
(46.19)\end{array}$ & $84.26 \%$ & $20.67 \%$ \\
\hline Quintile 3 & $\begin{array}{l}0.084 \\
(1.76)\end{array}$ & $\begin{array}{c}0.997 \\
(43.86)\end{array}$ & $83.51 \%$ & $25.52 \%$ \\
\hline Quintile 4 & $\begin{array}{l}0.172 \\
(3.81)\end{array}$ & $\begin{array}{c}0.934 \\
(42.89)\end{array}$ & $83.25 \%$ & $31.07 \%$ \\
\hline Quintile 5 (largest) & $\begin{array}{l}0.180 \\
(4.09)\end{array}$ & $\begin{array}{c}0.901 \\
(42.72)\end{array}$ & $83.33 \%$ & $44.22 \%$ \\
\hline Entire Sample & $\begin{array}{l}0.094 \\
(2.12)\end{array}$ & $\begin{array}{c}0.985 \\
(47.04)\end{array}$ & $86.57 \%$ & $26.63 \%$ \\
\hline \multicolumn{5}{|c|}{ Panel B: Elasticity of Supply } \\
\hline & Intercept & Slope Coefficient & $\operatorname{Adj} . R^{2}$ & $\begin{array}{c}\text { Mean Value of } \\
\text { Cancelled/Revised } \\
\text { Proportion }\end{array}$ \\
\hline Quintile 1 (smallest) & $\begin{array}{l}0.186 \\
(2.57)\end{array}$ & $\begin{array}{c}0.962 \\
(29.35)\end{array}$ & $81.92 \%$ & $8.54 \%$ \\
\hline Quintile 2 & $\begin{array}{l}0.389 \\
(8.34)\end{array}$ & $\begin{array}{c}0.846 \\
(38.48)\end{array}$ & $77.27 \%$ & $16.68 \%$ \\
\hline Quintile 3 & $\begin{array}{r}0.449 \\
(10.27)\end{array}$ & $\begin{array}{c}0.806 \\
(39.83)\end{array}$ & $77.15 \%$ & $20.86 \%$ \\
\hline Quintile 4 & $\begin{array}{r}0.489 \\
(12.25)\end{array}$ & $\begin{array}{c}0.776 \\
(40.15)\end{array}$ & $78.22 \%$ & $25.05 \%$ \\
\hline Quintile 5 (largest) & $\begin{array}{c}0.404 \\
(10.22)\end{array}$ & $\begin{array}{c}0.794 \\
(40.91)\end{array}$ & $82.36 \%$ & $33.59 \%$ \\
\hline Entire Sample & $\begin{array}{l}0.377 \\
(9.43)\end{array}$ & $\begin{array}{r}0.836 \\
(44.83) \\
\end{array}$ & $81.74 \%$ & $20.09 \%$ \\
\hline
\end{tabular}




\section{Table IV}

\section{Investor Classes and Elasticity of Demand and Supply}

This table reports the elasticity of demand and supply for the trading session following the opening auction (i.e., rest of trading hours) during the period December 1996 - December 2000. Investors are classified as domestic individuals (Individual), domestic institutions (Institution), and foreign investors (Foreign). For each firm and each investor type, the daily elasticity is estimated using the following regression: $p_{j k}=\alpha_{j}+\beta_{j} d_{j k}+\varepsilon_{j k}$; where $p_{j k}$ and $d_{j k}$ represent the normalized price and normalized cumulative quantity demanded by the investor class at tick point $k$ for firm $j$ on a given trading day. The daily elasticity is defined as the inverse of slope coefficient (i.e., $\left.\eta_{j}=1 /\left|\beta_{j}\right|\right)$. Then, the daily elasticity measures are averaged across all firms. The sample period is divided into three sub-periods: (a) pre-crisis period (December 1996 - October 1997), (b) in-crisis period (November 1997 - October 1998), and (c) post-crisis period (November 1998 - December 2000).

\begin{tabular}{|c|c|c|c|c|c|}
\hline \multicolumn{6}{|c|}{ Panel A: Elasticity of Demand } \\
\hline Sub-period & Investor class & $\mathrm{N}$ & Mean & Median & Std. Dev. \\
\hline \multirow{3}{*}{ Entire sample period } & Individual & 1,090 & 10.44 & 8.96 & 3.59 \\
\hline & Institution & 1,090 & 18.90 & 18.88 & 5.00 \\
\hline & Foreign & 1,090 & 21.77 & 21.46 & 6.07 \\
\hline \multirow[t]{3}{*}{ Pre-crisis period } & Individual & 265 & 15.83 & 15.93 & 1.72 \\
\hline & Institution & 265 & 22.63 & 22.54 & 3.58 \\
\hline & Foreign & 265 & 22.00 & 21.23 & 6.48 \\
\hline \multirow[t]{3}{*}{ In-crisis period } & Individual & 293 & 10.07 & 9.78 & 2.47 \\
\hline & Institution & 293 & 18.67 & 18.44 & 4.71 \\
\hline & Foreign & 293 & 20.16 & 19.49 & 5.91 \\
\hline \multirow[t]{3}{*}{ Post-crisis period } & Individual & 532 & 7.96 & 7.90 & 0.96 \\
\hline & Institution & 532 & 17.17 & 16.26 & 4.77 \\
\hline & Foreign & 532 & 22.55 & 22.40 & 5.77 \\
\hline \multicolumn{6}{|c|}{ Panel B: Elasticity of Supply } \\
\hline Sub-period & Investor class & $\mathrm{N}$ & Mean & Median & Std. Dev. \\
\hline \multirow[t]{3}{*}{ Entire sample period } & Individual & 1,090 & 9.32 & 8.10 & 3.01 \\
\hline & Institution & 1,090 & 19.59 & 19.24 & 5.32 \\
\hline & Foreign & 1,090 & 21.55 & 21.26 & 5.58 \\
\hline \multirow[t]{3}{*}{ Pre-crisis period } & Individual & 265 & 13.52 & 13.74 & 1.62 \\
\hline & Institution & 265 & 24.25 & 24.34 & 3.76 \\
\hline & Foreign & 265 & 22.22 & 21.39 & 5.07 \\
\hline \multirow[t]{3}{*}{ In-crisis period } & Individual & 293 & 9.15 & 8.64 & 2.59 \\
\hline & Institution & 293 & 19.07 & 18.59 & 4.55 \\
\hline & Foreign & 293 & 20.18 & 20.12 & 5.86 \\
\hline \multirow[t]{3}{*}{ Post-crisis period } & Individual & 532 & 7.32 & 7.26 & 0.90 \\
\hline & Institution & 532 & 17.55 & 16.47 & 4.94 \\
\hline & Foreign & 532 & 21.98 & 21.75 & 5.53 \\
\hline
\end{tabular}




\section{Table V \\ Summary Statistics for Potential Determinants of Elasticity}

This table reports the summary statistics for the time series of daily average of each variable for different periods. AdvCost is the adverse selection component of the spread, relative to the mid-point of bid and ask prices of buy (sell) orders. The adverse selection cost is calculated for buy orders and sell orders separately. Volat is the standard deviation of returns over the trading day where returns are measured using the bid-ask mid-point in 5-minute intervals. Volume is the daily trading volume divided by the number of shares outstanding. $\mathrm{Mrg}$ is the ratio of margin buy orders to total buy orders submitted while Sht is the ratio of short sale orders to total sell orders submitted. The sample period is divided into three sub-periods: (a) pre-crisis period (December 1996 - October 1997), (b) in-crisis period (November 1997 - October 1998), and (c) post-crisis period (November 1998 - December 2000)

\begin{tabular}{|c|c|c|c|c|c|}
\hline Sub-period & Variable & $\mathrm{N}$ & Mean & Median & Std. Dev. \\
\hline \multirow{6}{*}{ Entire sample period } & AdvCost-Buy (\%) & 1,090 & 0.853 & 0.751 & 0.348 \\
\hline & AdvCost-Sell (\%) & 1,090 & 1.087 & 0.931 & 0.482 \\
\hline & Volat $(\%)$ & 1,090 & 0.661 & 0.638 & 0.165 \\
\hline & Volume (\%) & 1,090 & 1.631 & 1.389 & 0.988 \\
\hline & $\operatorname{Mrg}(\%)$ & 1,090 & 7.123 & 2.665 & 8.305 \\
\hline & Sht $(\%)$ & 1090 & 0.155 & 0.004 & 0.264 \\
\hline \multirow{6}{*}{ Pre-crisis period } & AdvCost-Buy (\%) & 265 & 0.755 & 0.661 & 0.236 \\
\hline & AdvCost-Sell (\%) & 265 & 0.917 & 0.812 & 0.305 \\
\hline & Volat (\%) & 265 & 0.542 & 0.519 & 0.113 \\
\hline & Volume (\%) & 265 & 0.773 & 0.787 & 0.192 \\
\hline & $\operatorname{Mrg}(\%)$ & 265 & 20.364 & 20.234 & 2.879 \\
\hline & Sht $(\%)$ & 265 & 0.481 & 0.428 & 0.241 \\
\hline \multirow[t]{6}{*}{ In-crisis period } & AdvCost-Buy (\%) & 293 & 1.253 & 1.197 & 0.331 \\
\hline & AdvCost-Sell (\%) & 293 & 1.625 & 1.519 & 0.525 \\
\hline & Volat (\%) & 293 & 0.802 & 0.782 & 0.158 \\
\hline & Volume (\%) & 293 & 0.991 & 0.957 & 0.329 \\
\hline & $\operatorname{Mrg}(\%)$ & 293 & 5.748 & 3.179 & 5.034 \\
\hline & Sht $(\%)$ & 293 & 0.140 & 0.025 & 0.260 \\
\hline \multirow[t]{6}{*}{ Post-crisis period } & AdvCost-Buy (\%) & 532 & 0.682 & 0.650 & 0.197 \\
\hline & AdvCost-Sell (\%) & 532 & 0.875 & 0.836 & 0.244 \\
\hline & Volat (\%) & 532 & 0.644 & 0.618 & 0.130 \\
\hline & Volume (\%) & 532 & 2.411 & 2.251 & 0.849 \\
\hline & $\operatorname{Mrg}(\%)$ & 532 & 1.284 & 0.987 & 0.846 \\
\hline & Sht $(\%)$ & 532 & 0.000 & 0.000 & 0.001 \\
\hline
\end{tabular}




\section{Table VI}

\section{Time-Series Regression Results for Determinants of Elasticity}

This table reports the time-series regression results for the determinants of elasticity. The elasticity is measured by using orders submitted during the session following the opening auction (i.e., the rest of trading hours). The sample period is divided into three sub-periods: (a) pre-crisis period (December 1996 - October 1997), (b) in-crisis period (November 1997 - October 1998), and (c) post-crisis period (November 1998 - December 2000). The determinants of elasticity are examined using the following regressions:

$$
\begin{gathered}
\eta_{t}=b_{0}+b_{1} \text { AdvCost }_{t}+b_{3} \text { Volume }_{t}+b_{4} \text { Mrg }_{t}+b_{5} t+\varepsilon_{t} \\
\eta_{t}=b_{0}+b_{2} \text { Volat }_{t}+b_{3} \text { Volume }_{t}+b_{4} \text { Mrg }_{t}+b_{5} t+v_{t}
\end{gathered}
$$

$\eta_{t}$ is the magnitude of elasticity on trading day $t$. AdvCost $t_{t}$ is the adverse selection component of spread. Volat $t_{t}$ is the standard deviation of returns over the trading day where returns are measured using the bid-ask mid-point in 5-minute intervals. Volume $t_{t}$ is the daily trading volume divided by the number of shares outstanding. $\mathrm{Mrg}_{t}$ is the ratio of margin-buy orders to total buy orders. All variables are averaged across all firms to obtain the daily aggregate measures. Then, they are transformed by adding a value of one and then by taking natural logarithms. $t$ is the trend variable. Values in parentheses represent $t$-statistics which are adjusted for serial correlation and heteroskedasticity using the generalized method of moments (GMM) with the Newey-West (1989)

\begin{tabular}{|c|c|c|c|c|c|c|c|c|}
\hline \multicolumn{9}{|c|}{ Panel A: Elasticity of Demand } \\
\hline & \multicolumn{2}{|c|}{$\frac{\text { Entire sample }}{\text { period }}$} & \multicolumn{2}{|c|}{ Pre-crisis period } & \multicolumn{2}{|c|}{ In-crisis period } & \multicolumn{2}{|c|}{ Post-crisis period } \\
\hline & Model 1 & Model 2 & Model 1 & Model 2 & Model 1 & Model 2 & Model 1 & Model 2 \\
\hline $\begin{array}{l}\text { No. of } \\
\text { days }\end{array}$ & 1,090 & 1,090 & 265 & 265 & 293 & 293 & 532 & 532 \\
\hline Intercept & $\begin{array}{r}3.290 \\
(21.51)\end{array}$ & $\begin{array}{r}3.086 \\
(25.05)\end{array}$ & $\begin{array}{r}3.904 \\
(11.50)\end{array}$ & $\begin{array}{r}2.886 \\
(13.66)\end{array}$ & $\begin{array}{r}0.741 \\
(1.22)\end{array}$ & $\begin{array}{l}1.704 \\
(2.60)\end{array}$ & $\begin{array}{l}1.449 \\
(1.66)\end{array}$ & $\begin{array}{r}2.197 \\
(2.56)\end{array}$ \\
\hline$A d v \operatorname{Cost}$ & $\begin{array}{r}-0.541 \\
(-10.32)\end{array}$ & & $\begin{array}{l}-0.884 \\
(-7.24)\end{array}$ & & $\begin{array}{l}-0.540 \\
(-6.35)\end{array}$ & & $\begin{array}{l}-0.470 \\
(-5.80)\end{array}$ & \\
\hline Volat & & $\begin{array}{r}-0.912 \\
(-13.12)\end{array}$ & & $\begin{array}{l}-1.034 \\
(-7.54)\end{array}$ & & $\begin{array}{c}-0.919 \\
(-5.11)\end{array}$ & & $\begin{array}{r}-0.722 \\
(-8.36)\end{array}$ \\
\hline Volume & $\begin{array}{l}-0.375 \\
(-7.34)\end{array}$ & $\begin{array}{l}-0.244 \\
(-6.86)\end{array}$ & $\begin{array}{l}-0.495 \\
(-7.13)\end{array}$ & $\begin{array}{l}-0.252 \\
(-3.31)\end{array}$ & $\begin{array}{l}-0.760 \\
(-6.34)\end{array}$ & $\begin{array}{l}-0.643 \\
(-6.01)\end{array}$ & $\begin{array}{l}-0.194 \\
(-3.52)\end{array}$ & $\begin{array}{l}-0.084 \\
(-1.81)\end{array}$ \\
\hline Mrg & $\begin{array}{r}0.108 \\
(5.18)\end{array}$ & $\begin{array}{r}0.135 \\
(7.84)\end{array}$ & $\begin{array}{r}0.024 \\
(0.33)\end{array}$ & $\begin{array}{r}0.189 \\
(2.93)\end{array}$ & $\begin{array}{r}0.166 \\
(3.38)\end{array}$ & $\begin{array}{r}0.141 \\
(3.38)\end{array}$ & $\begin{array}{c}0.286 \\
(4.45)\end{array}$ & $\begin{array}{r}0.204 \\
(3.00)\end{array}$ \\
\hline$t$ & $\begin{array}{r}-0.069 \\
(-4.96)\end{array}$ & $\begin{array}{l}-0.040 \\
(-3.37)\end{array}$ & $\begin{array}{l}-0.088 \\
(-4.57)\end{array}$ & $\begin{array}{l}-0.016 \\
(-1.61)\end{array}$ & $\begin{array}{r}0.381 \\
(4.10)\end{array}$ & $\begin{array}{l}0.232 \\
(2.53)\end{array}$ & $\begin{array}{r}0.147 \\
(1.25)\end{array}$ & $\begin{array}{r}0.042 \\
(0.35)\end{array}$ \\
\hline $\operatorname{Adj} . R^{2}$ & $82.44 \%$ & $83.53 \%$ & $36.52 \%$ & $32.09 \%$ & $35.54 \%$ & $38.01 \%$ & $51.92 \%$ & $58.29 \%$ \\
\hline
\end{tabular}
procedure. 
Panel B: Elasticity of Supply

\begin{tabular}{|c|c|c|c|c|c|c|c|c|}
\hline & \multicolumn{2}{|c|}{$\frac{\text { Entire sample }}{\text { period }}$} & \multicolumn{2}{|c|}{ Pre-crisis period } & \multicolumn{2}{|c|}{ In-crisis period } & \multicolumn{2}{|c|}{ Post-crisis period } \\
\hline & Model 1 & Model 2 & Model 1 & $\begin{array}{c}\text { Model } \\
2\end{array}$ & $\begin{array}{c}\text { Model } \\
1\end{array}$ & Model 2 & Model 1 & Model 2 \\
\hline $\begin{array}{l}\text { No. of } \\
\text { days }\end{array}$ & 1,090 & 1,090 & 265 & 265 & 293 & 293 & 532 & 532 \\
\hline Intercept & $\begin{array}{r}2.875 \\
(19.09)\end{array}$ & $\begin{array}{r}2.432 \\
(20.16)\end{array}$ & $\begin{array}{r}3.351 \\
(11.38)\end{array}$ & $\begin{array}{l}1.595 \\
(6.88)\end{array}$ & $\begin{array}{l}1.670 \\
(2.15)\end{array}$ & $\begin{array}{c}-0.368 \\
(-0.44)\end{array}$ & $\begin{array}{c}1.644 \\
(1.99)\end{array}$ & $\begin{array}{c}1.656 \\
(1.78)\end{array}$ \\
\hline$A d v \operatorname{Cost}$ & $\begin{array}{l}-0.484 \\
(-9.14)\end{array}$ & & $\begin{array}{c}-0.966 \\
(-8.54)\end{array}$ & & $\begin{array}{l}-0.616 \\
(-5.72)\end{array}$ & & $\begin{array}{r}-0.489 \\
(-6.63)\end{array}$ & \\
\hline Volat & & $\begin{array}{c}-0.516 \\
(-7.39)\end{array}$ & & $\begin{array}{l}-0.951 \\
(-6.61)\end{array}$ & & $\begin{array}{c}0.152 \\
(0.61)\end{array}$ & & $\begin{array}{l}-0.657 \\
(-6.43)\end{array}$ \\
\hline Volume & $\begin{array}{l}-0.186 \\
(-4.91)\end{array}$ & $\begin{array}{c}0.018 \\
(0.52)\end{array}$ & $\begin{array}{r}-0.676 \\
(-11.27)\end{array}$ & $\begin{array}{l}-0.257 \\
(-4.00)\end{array}$ & $\begin{array}{r}0.099 \\
(0.71)\end{array}$ & $\begin{array}{c}0.444 \\
(3.19)\end{array}$ & $\begin{array}{l}-0.074 \\
(-1.64)\end{array}$ & $\begin{array}{c}0.055 \\
(1.56)\end{array}$ \\
\hline$M r g$ & $\begin{array}{r}0.147 \\
(7.54)\end{array}$ & $\begin{array}{r}0.195 \\
(11.54)\end{array}$ & $\begin{array}{c}0.211 \\
(3.38)\end{array}$ & $\begin{array}{r}0.521 \\
(6.75)\end{array}$ & $\begin{array}{r}0.107 \\
(1.84)\end{array}$ & $\begin{array}{c}0.199 \\
(3.62)\end{array}$ & $\begin{array}{r}0.259 \\
(4.02)\end{array}$ & $\begin{array}{c}0.236 \\
(3.04)\end{array}$ \\
\hline$t$ & $\begin{array}{l}-0.050 \\
(-3.55)\end{array}$ & $\begin{array}{l}-0.034 \\
(-1.98)\end{array}$ & $\begin{array}{l}-0.070 \\
(-4.84)\end{array}$ & $\begin{array}{r}0.009 \\
(0.89)\end{array}$ & $\begin{array}{r}0.158 \\
(1.39)\end{array}$ & $\begin{array}{r}0.320 \\
(2.75)\end{array}$ & $\begin{array}{c}0.099 \\
(0.88)\end{array}$ & $\begin{array}{r}0.079 \\
(0.61)\end{array}$ \\
\hline $\operatorname{Adj} . R^{2}$ & $78.96 \%$ & $73.39 \%$ & $66.97 \%$ & $34.70 \%$ & $39.37 \%$ & $19.78 \%$ & $51.80 \%$ & $47.79 \%$ \\
\hline
\end{tabular}


Figure 1: Time-Series Pattern of KOSPI index

This figure plots the time-series pattern of the Korea Composite Stock Price Index (KOSPI) during the period December 1996 - December 2000.

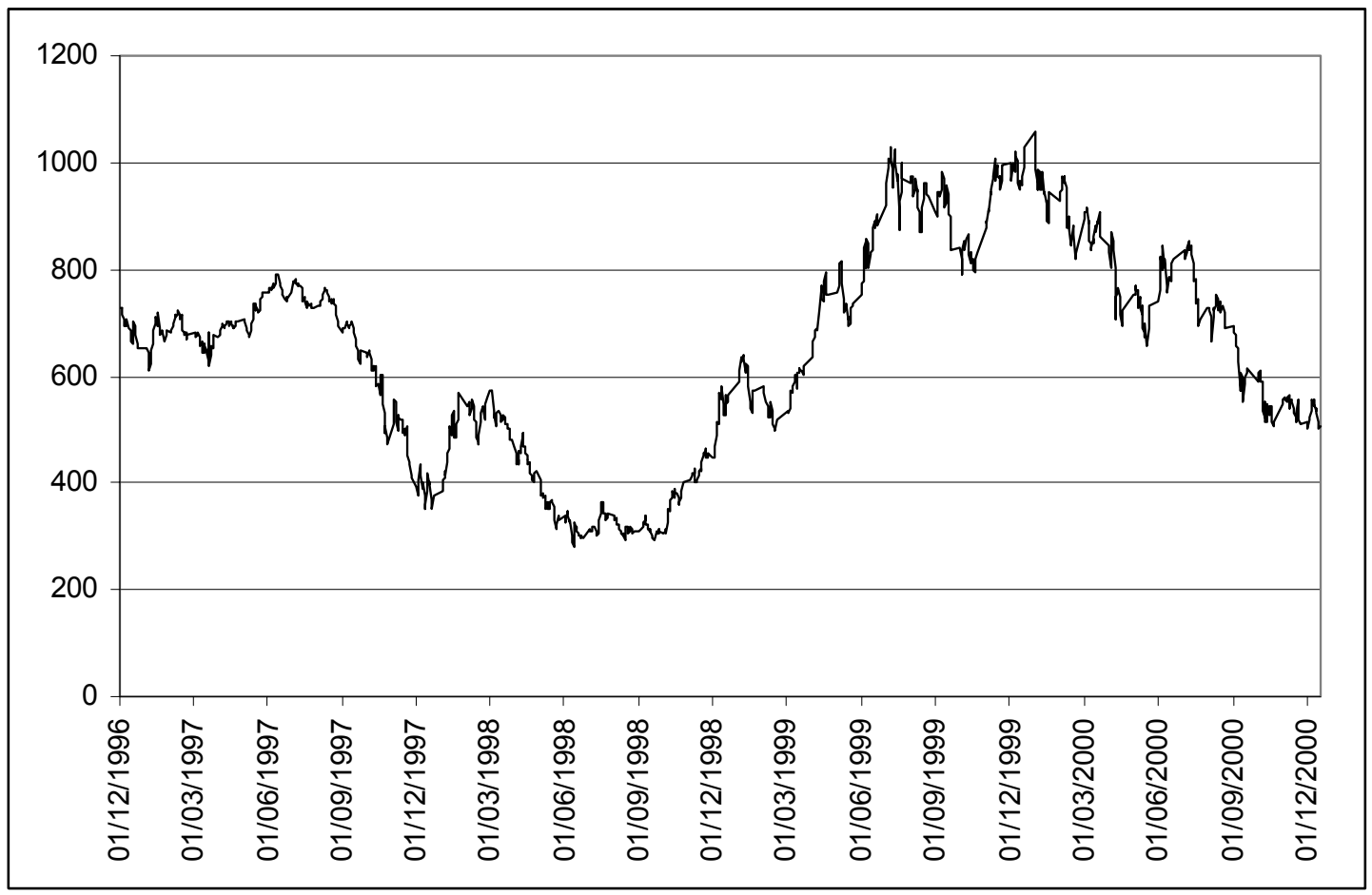


Figure 2: Time-Series Patterns of Demand Elasticities

This figure plots the cross-sectional averages of demand elasticities for the opening auction and the rest of trading hours.

(a) Opening auction

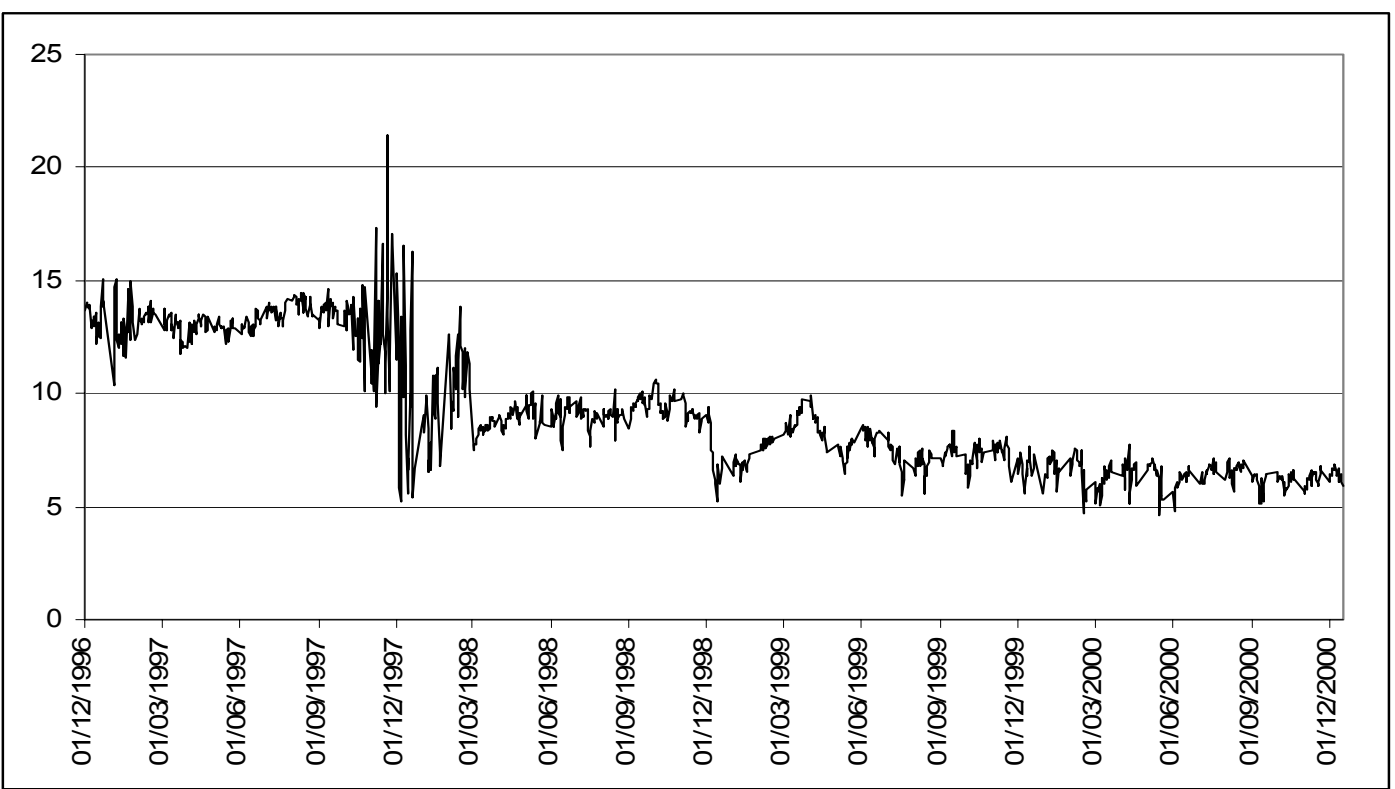

Time-Series Patterns of Average Elasticity for Demand Curves

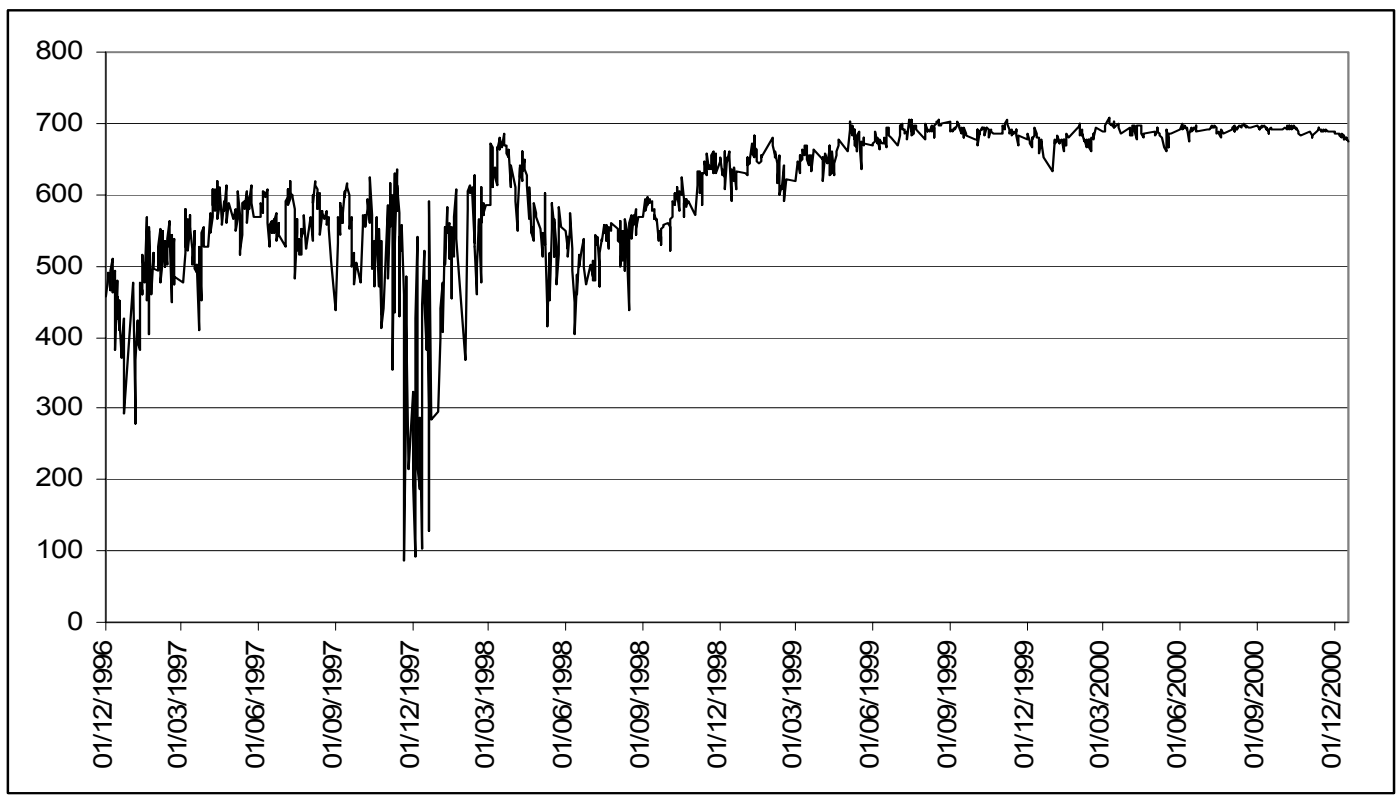

Number of Firms Used to Estimate Demand Curves 
(b) Rest of the Day

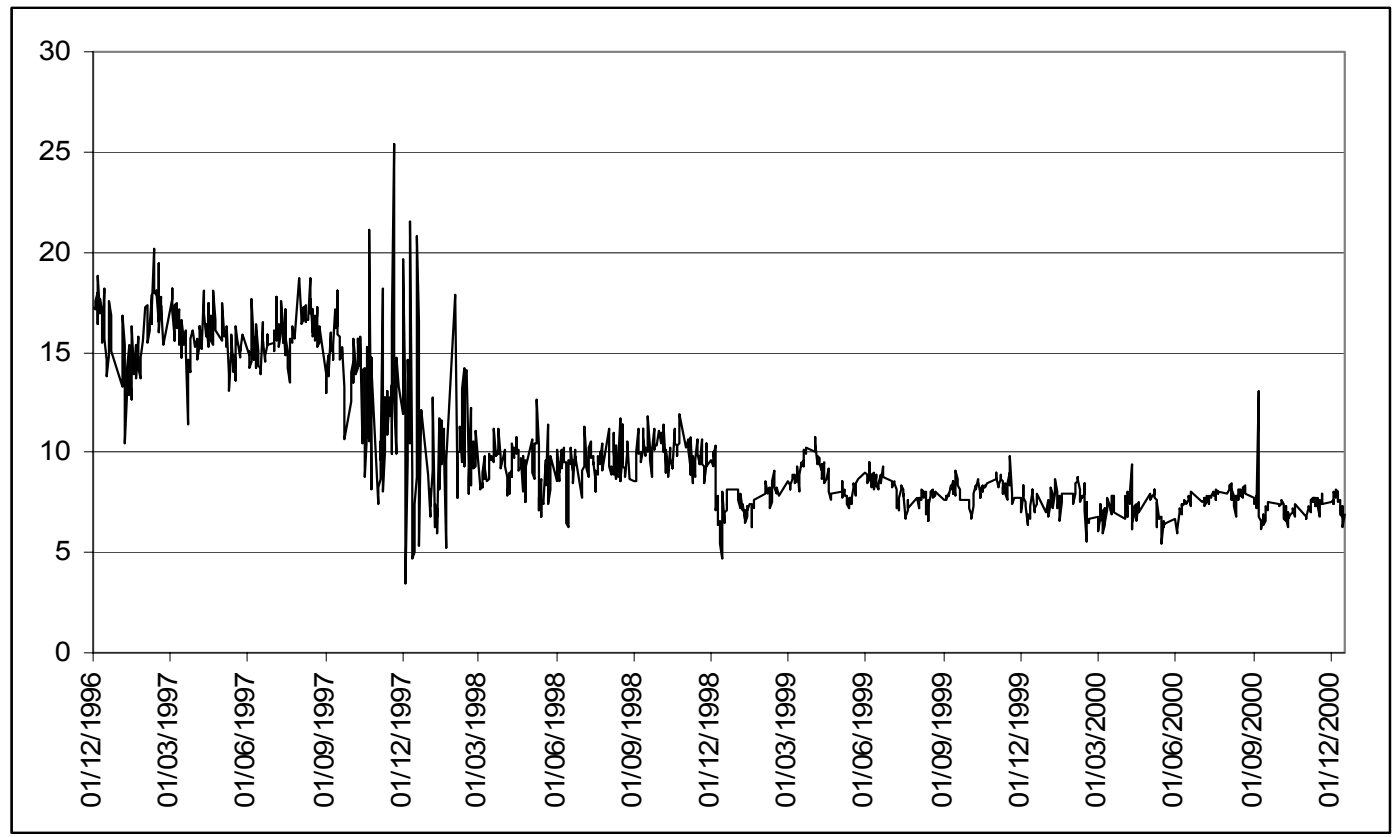

Time-Series Pattern of Average Elasticity for Demand Curves

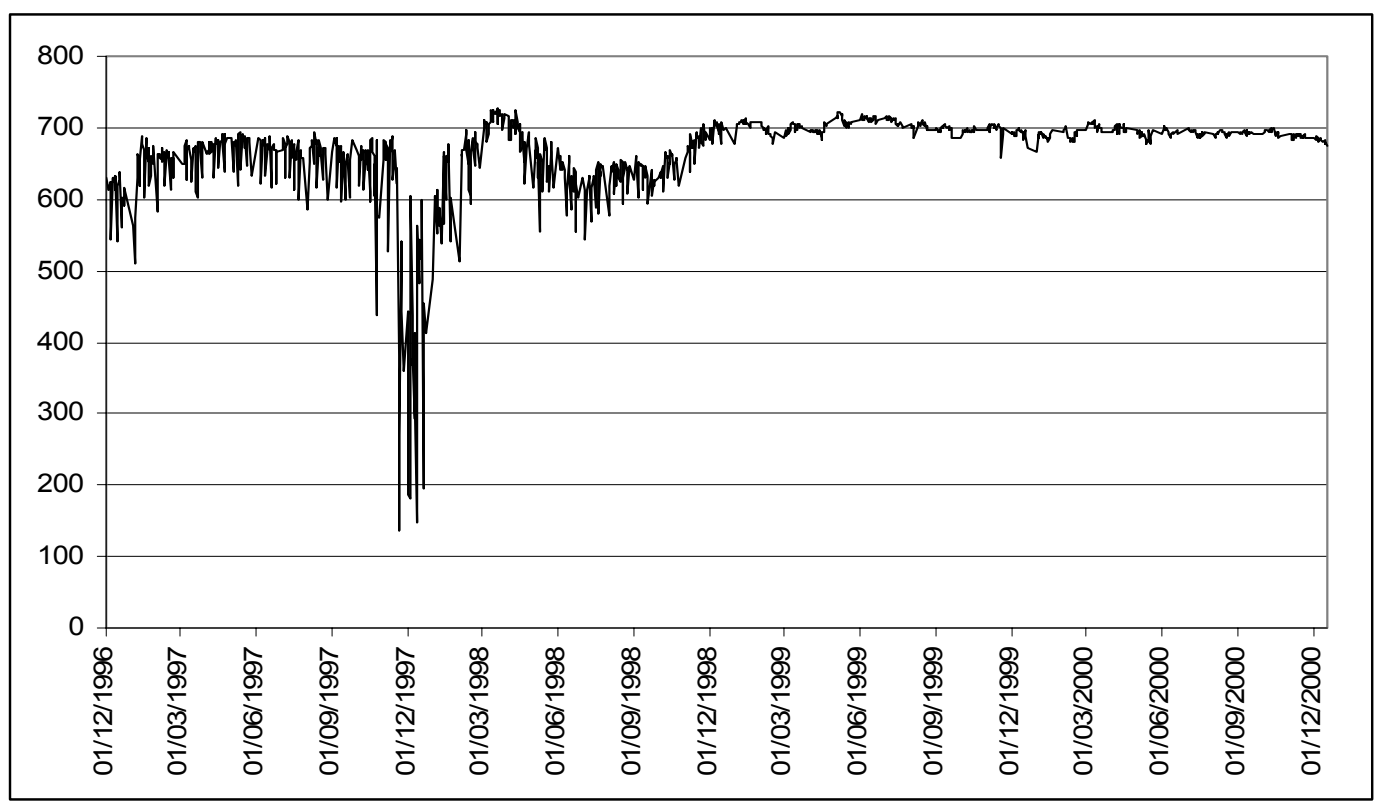

Number of Firms Used to Estimate Demand Curves 
Figure 3: Time-Series Patterns of Supply Elasticities

This figure plots the cross-sectional averages of supply elasticities for the opening auction and the rest of trading hours.

(a) Opening auction

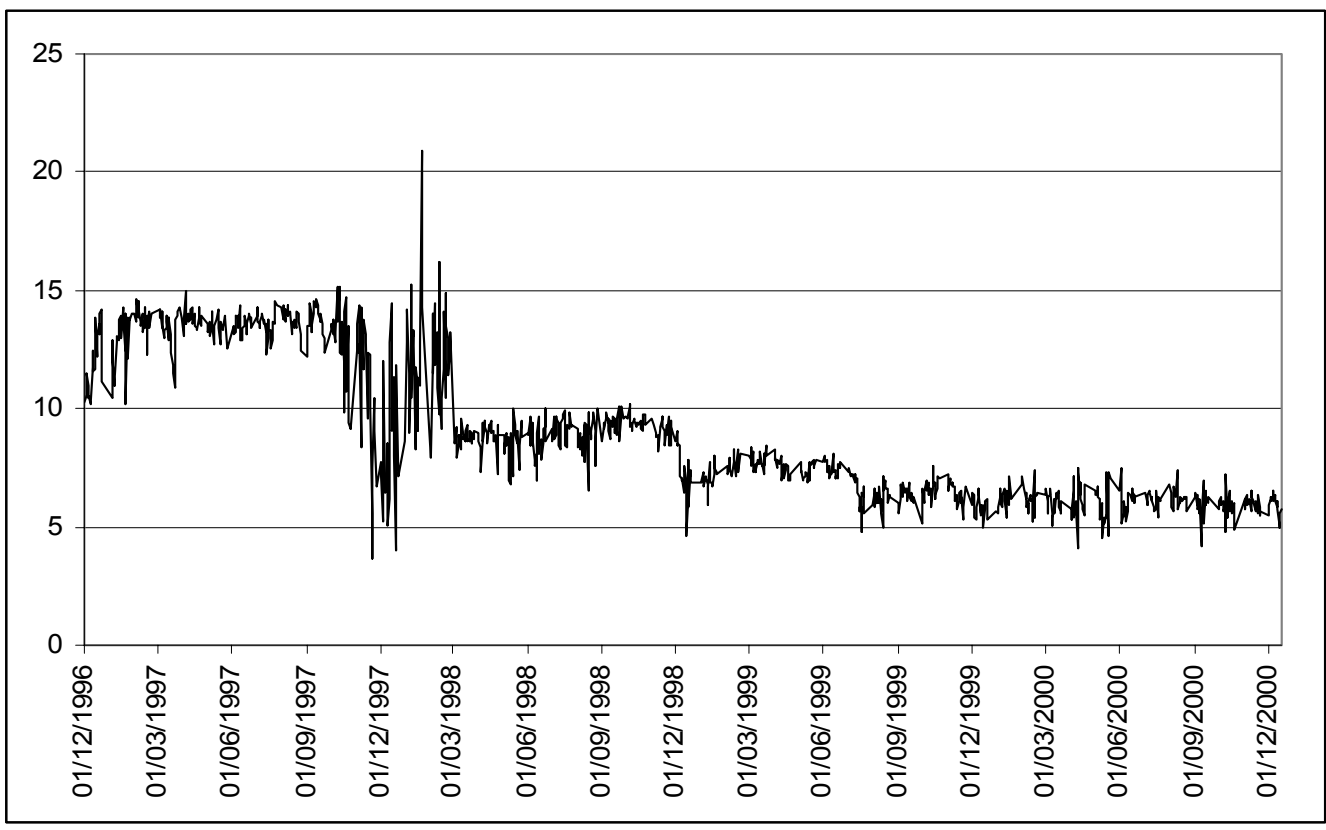

Time-Series Pattern of Average Elasticity for Supply Curves

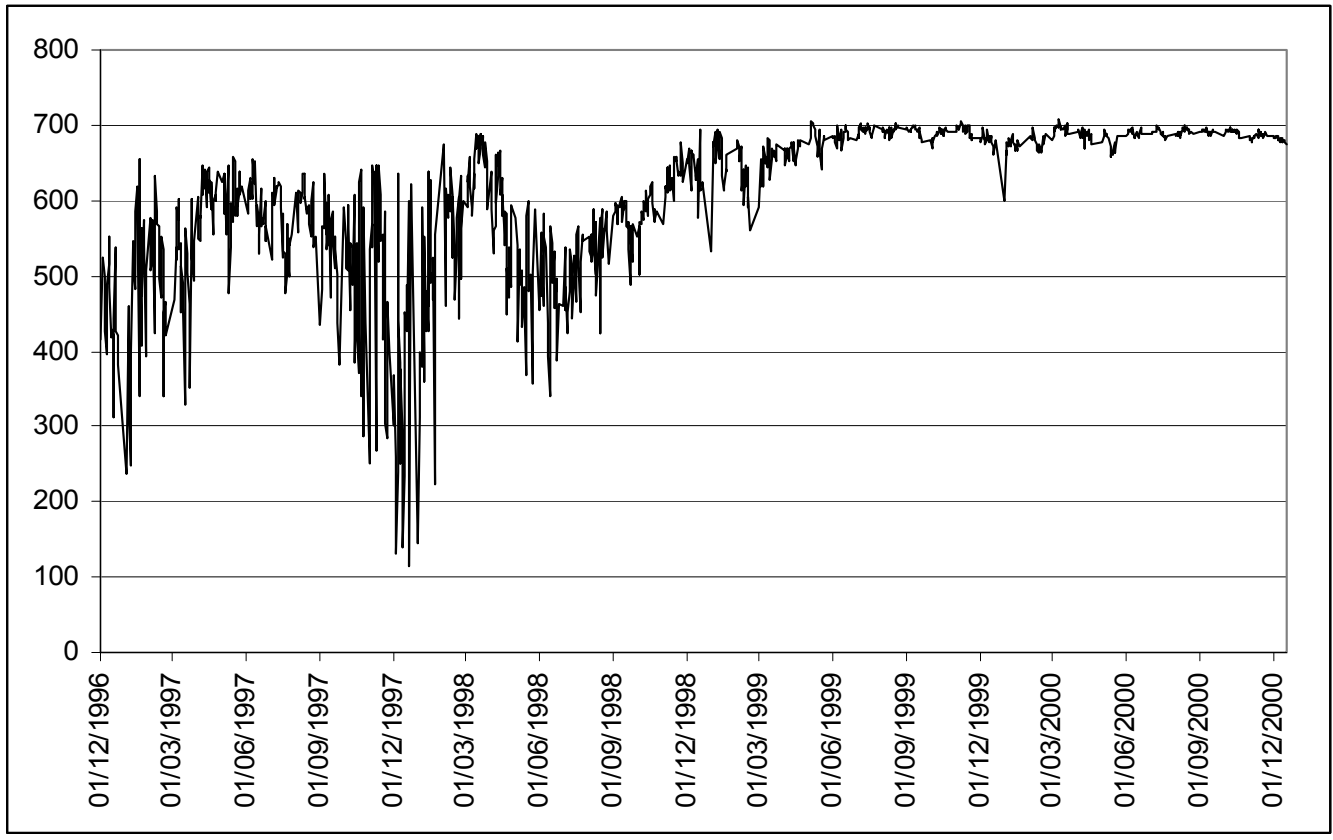

Number of Firms Used to Estimate Supply Curves 
(b) Rest-of-the-Day Supply Curves

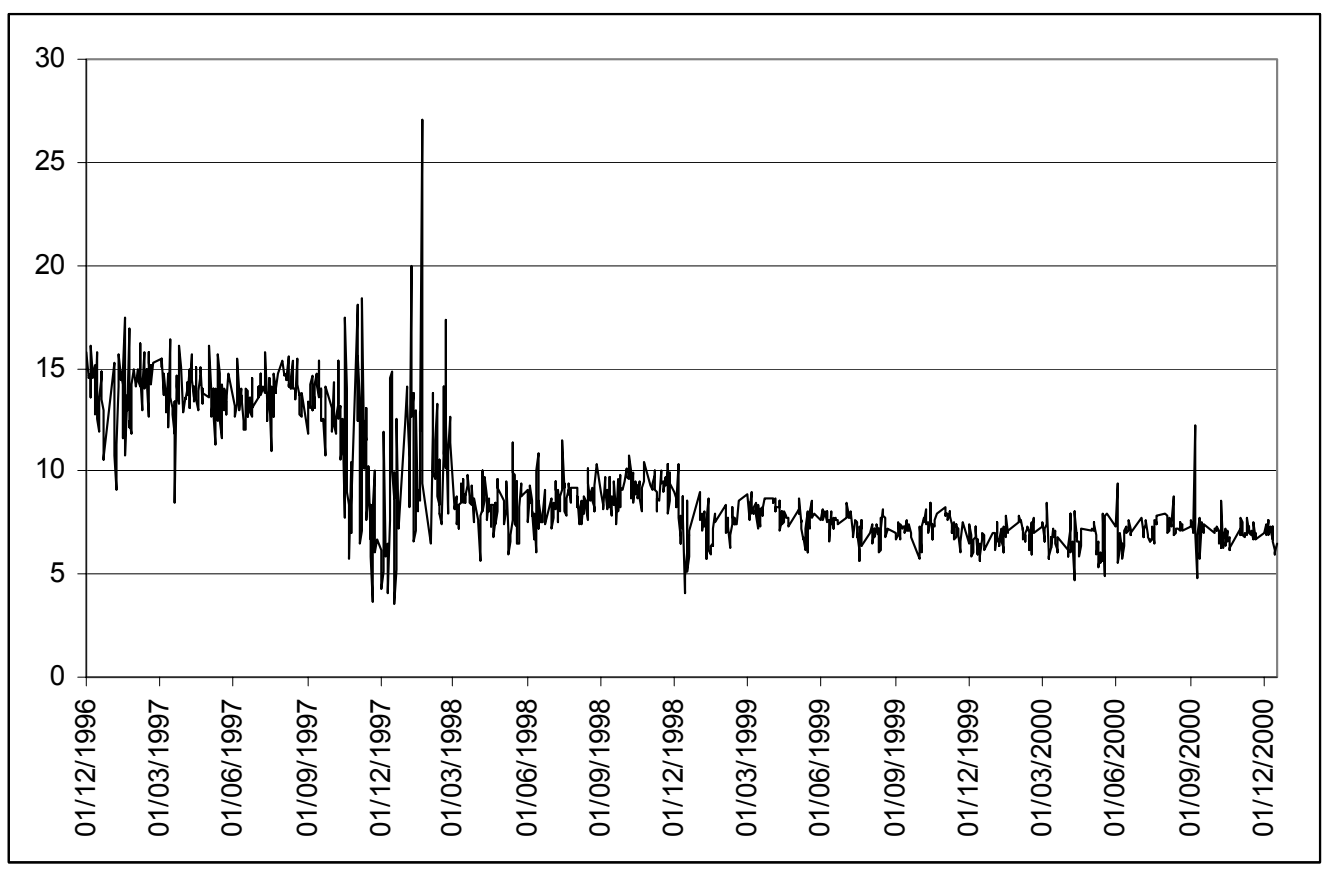

Time-Series Pattern of Average Elasticity for Supply Curves

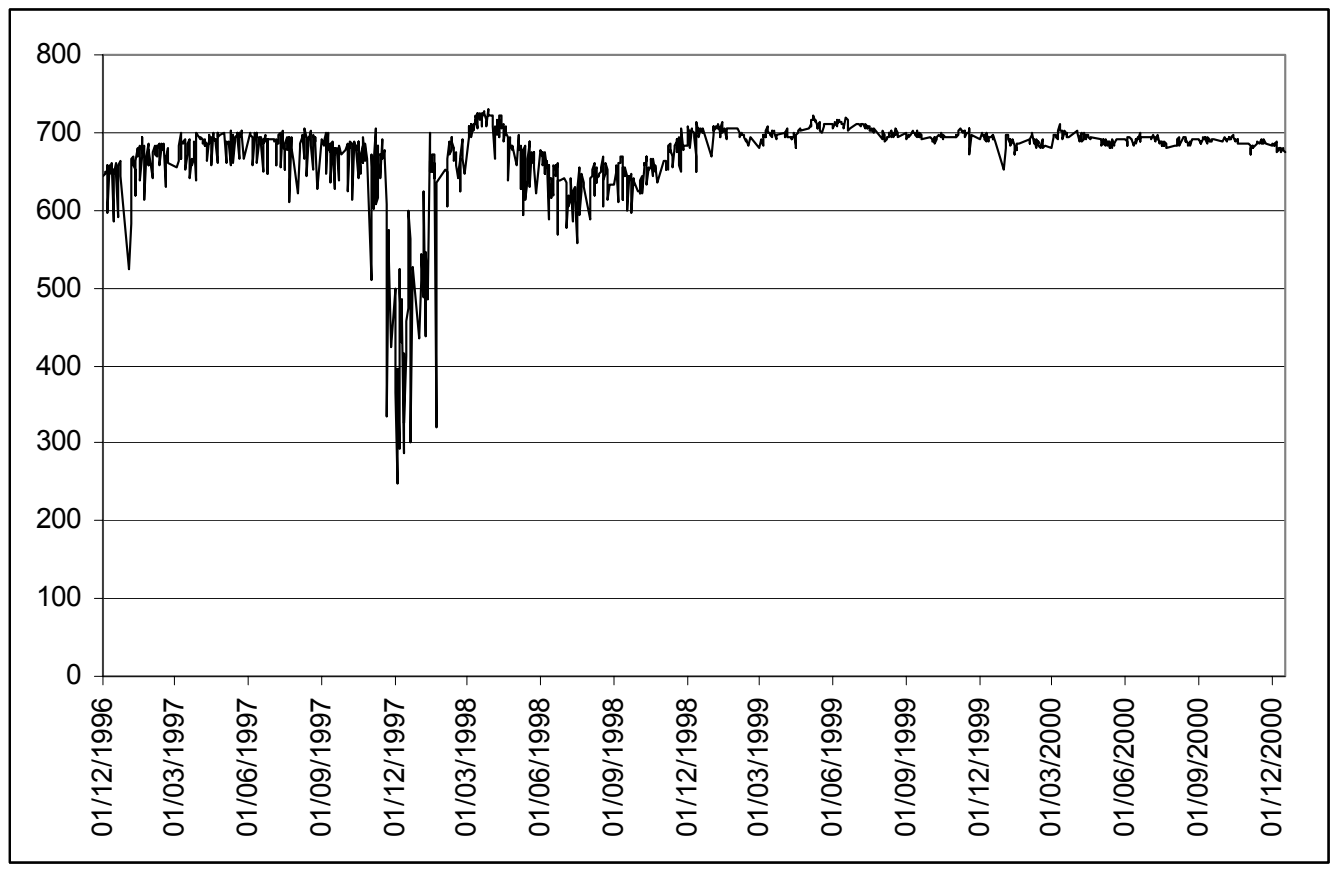

Number of Firms Used to Estimate Supply Curves 


\section{Figure 4: Demand and Supply Elasticities by Investor Type (Unrestricted Sample)}

This figure plots the time-series patterns of demand and supply elasticities of three investor classes: (1) domestic individual investors, (2) domestic institutional investors, and (3) foreign investors.

(a) Demand Elasticities

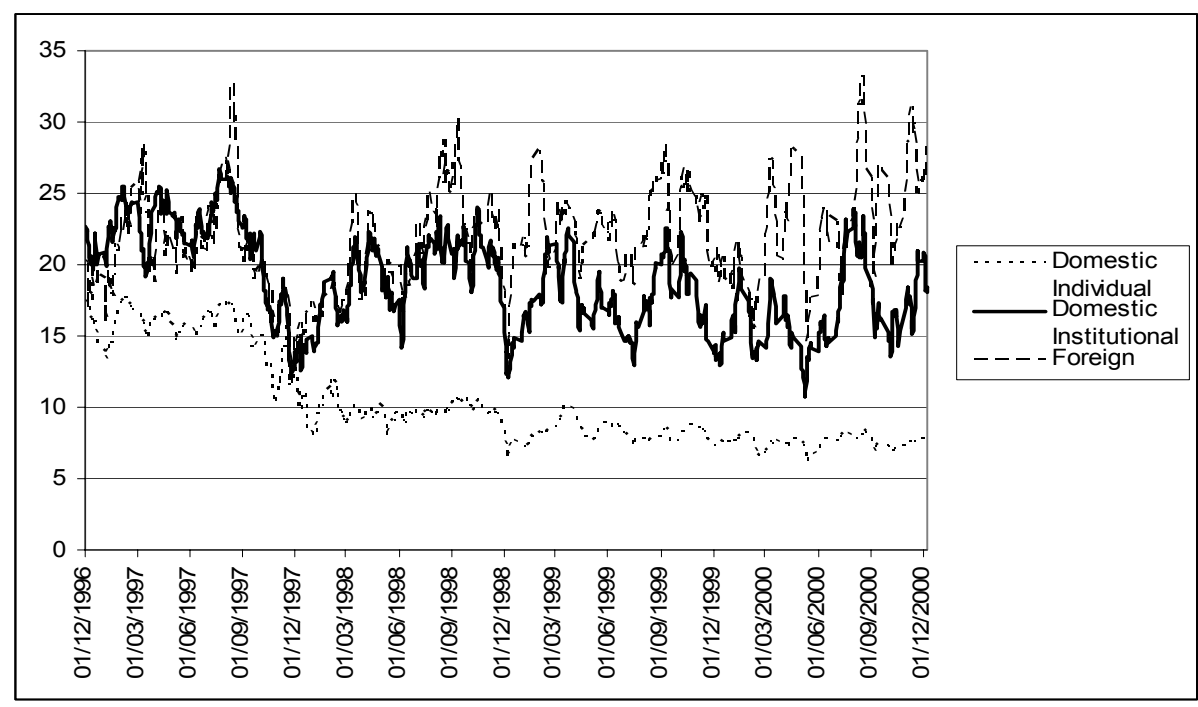

10-day Moving Average of Demand Elasticities

(b) Supply Elasticities

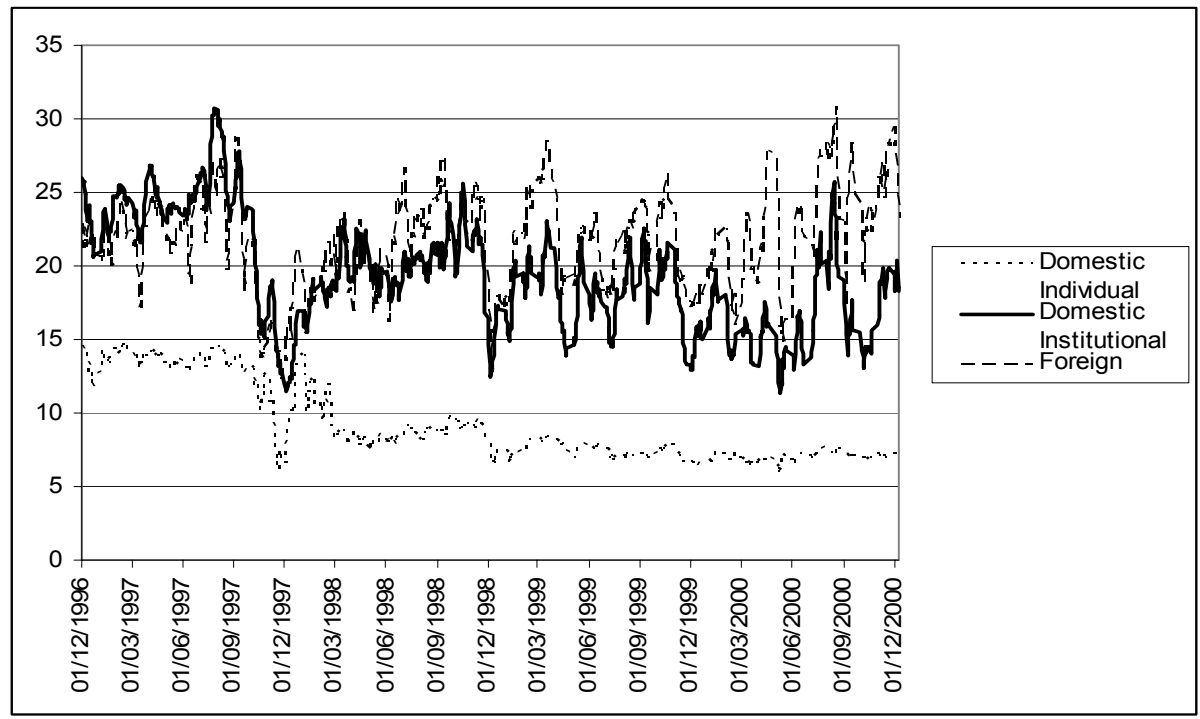

10-day Moving Average of Supply Elasticities 
Figure 5: Demand and Supply Elasticities by Investor Type (Restricted Sample)

This figure plots the time-series patterns of demand and supply elasticities by investor type using a restricted sample of firm-days that have elasticity measures for all three investor types: (1) domestic individual investors, (2) domestic institutional investors, and (3) foreign investors.

(a) Demand Elasticities

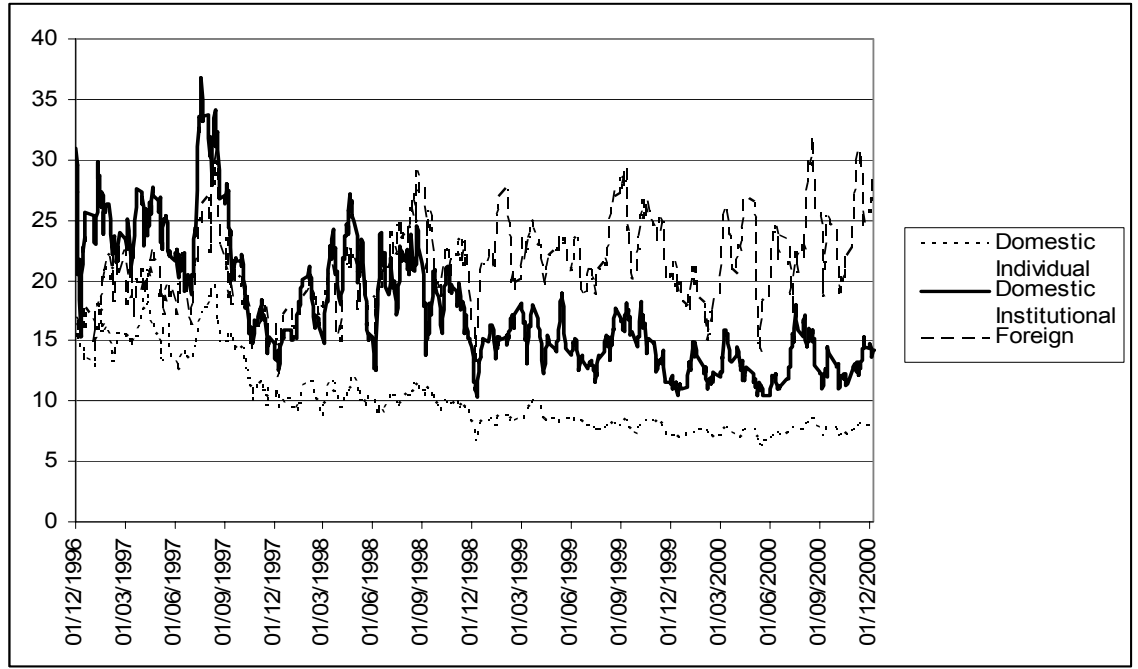

10-day Moving Average of Demand Elasticities

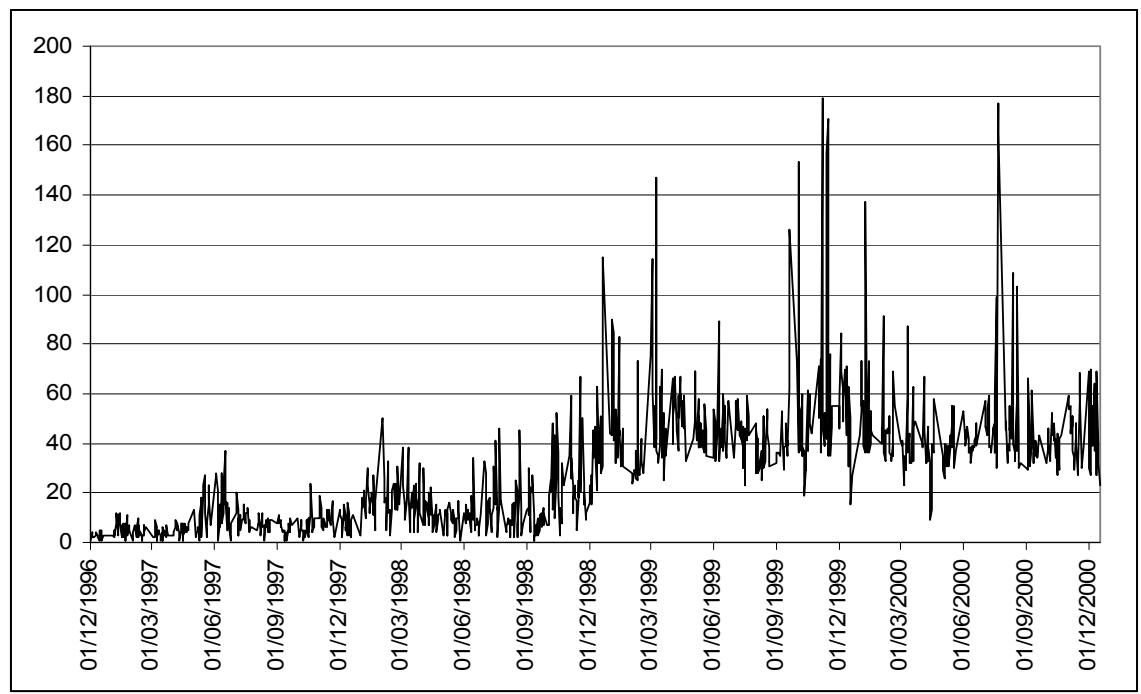

Number of Firms used to Estimate Elasticities 
(b) Supply Elasticities

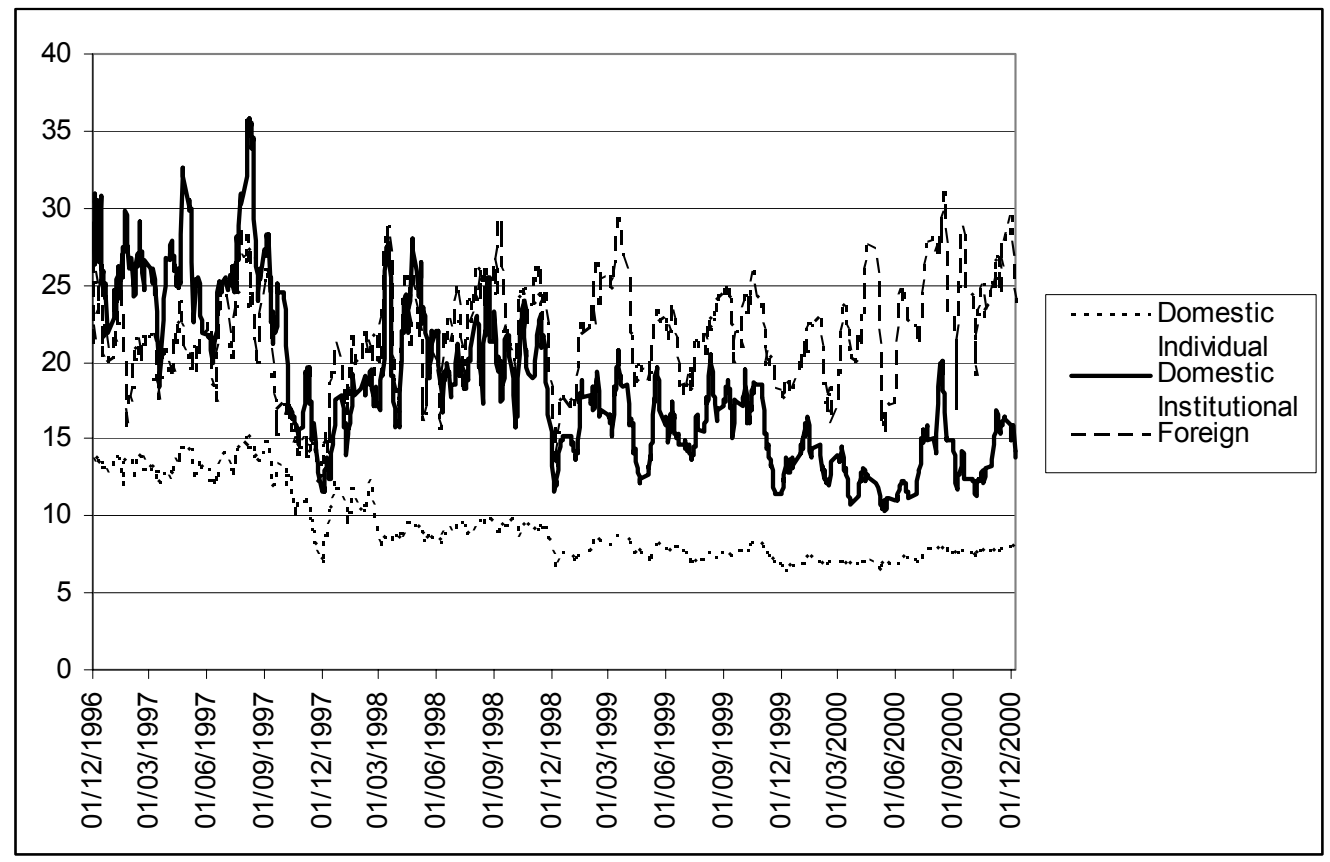

10-day Moving Average of Supply Elasticities

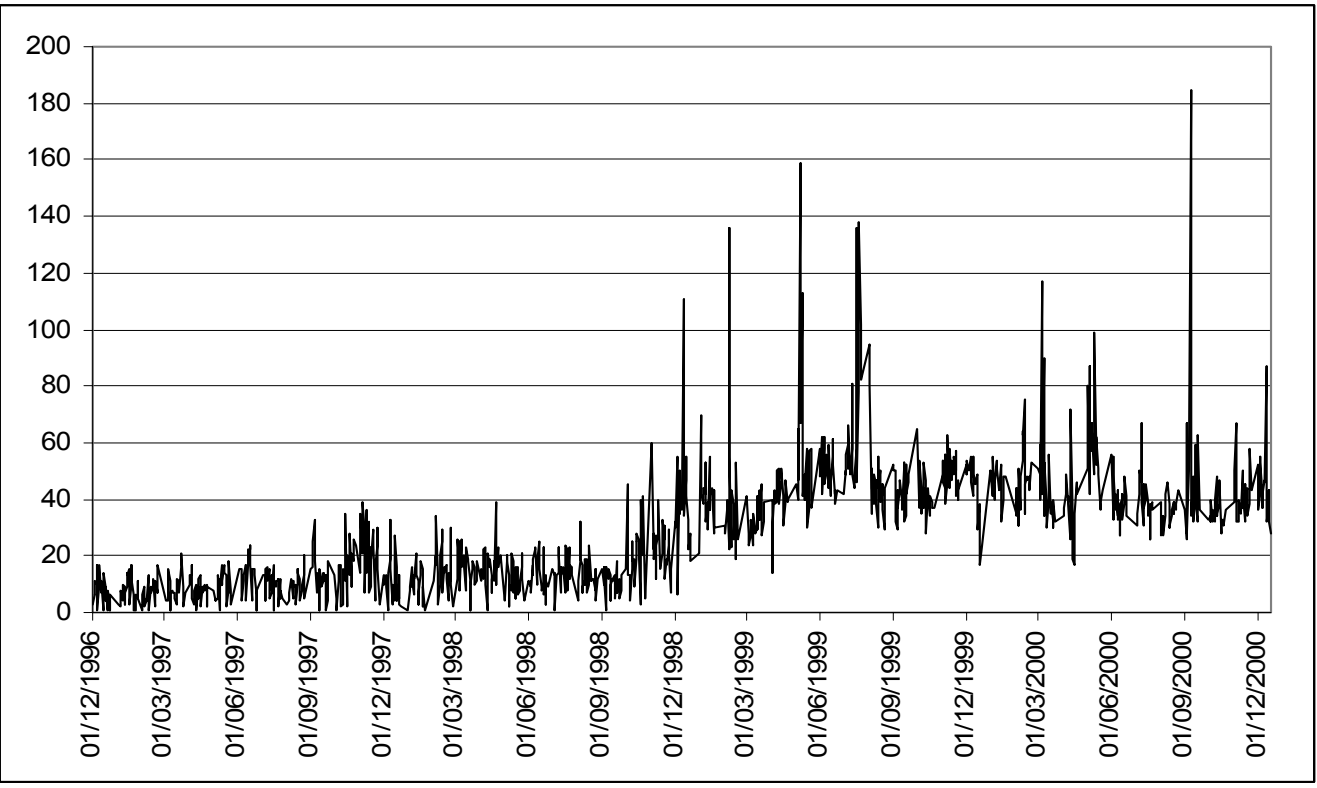

Number of Firms used to Estimate Elasticities 
Figure 6: Time-Series Patterns of Potential Determinants of Elasticities

This figure plots cross-sectional averages of potential determinants of demand and supply elasticities over the sample period.

(a) Adverse Selection Component of the Spread (Buy Orders)

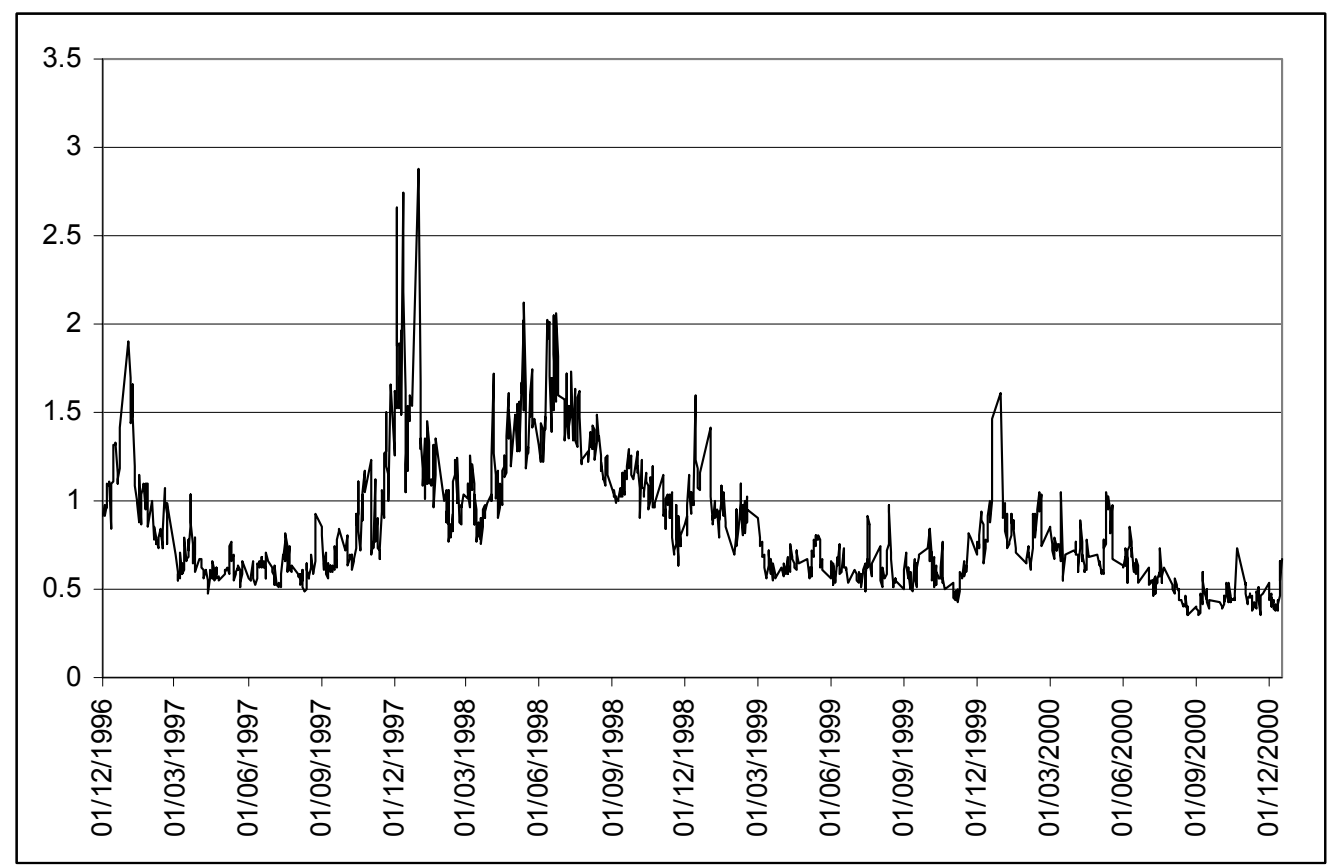

(b) Adverse Selection Component of the Spread (Sell Orders)

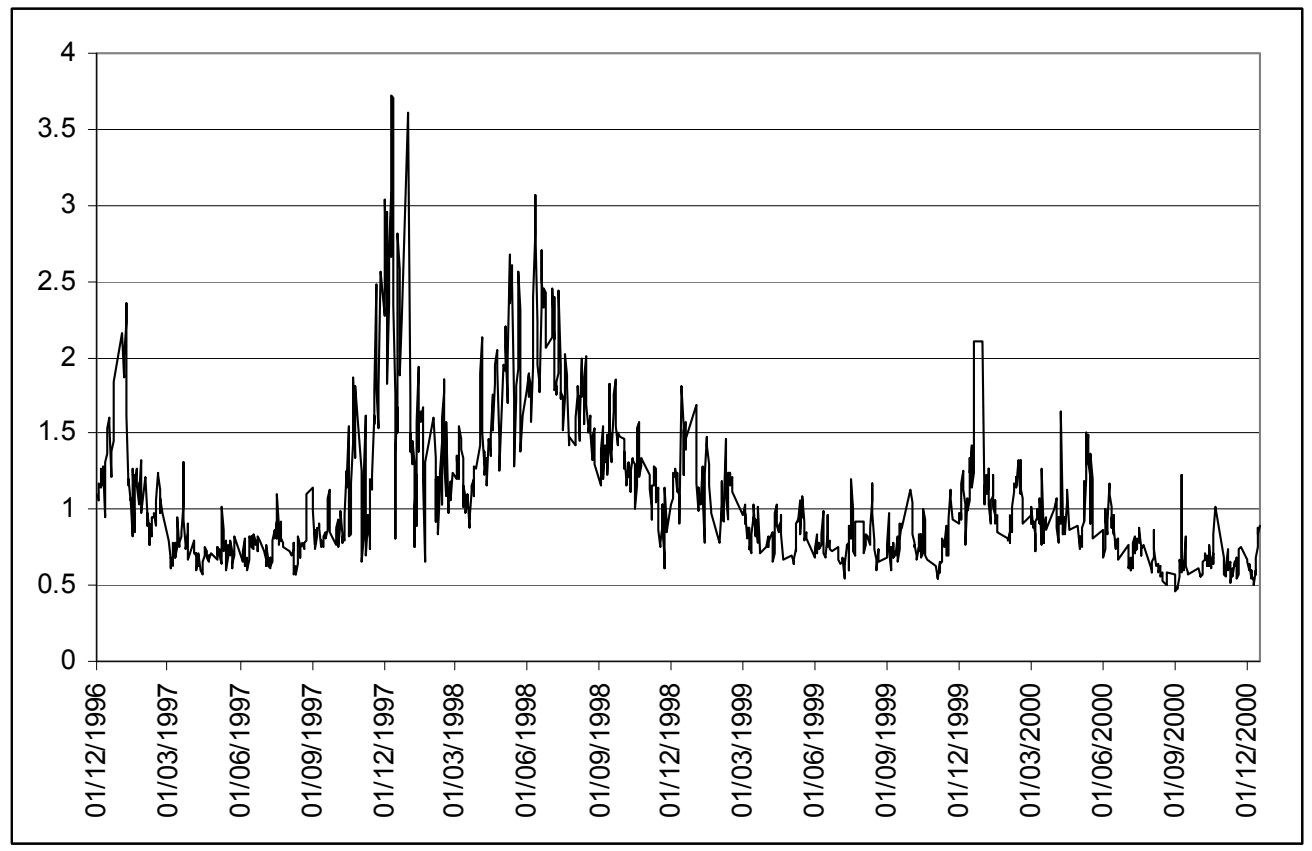


(c) Intraday Volatility (\%)

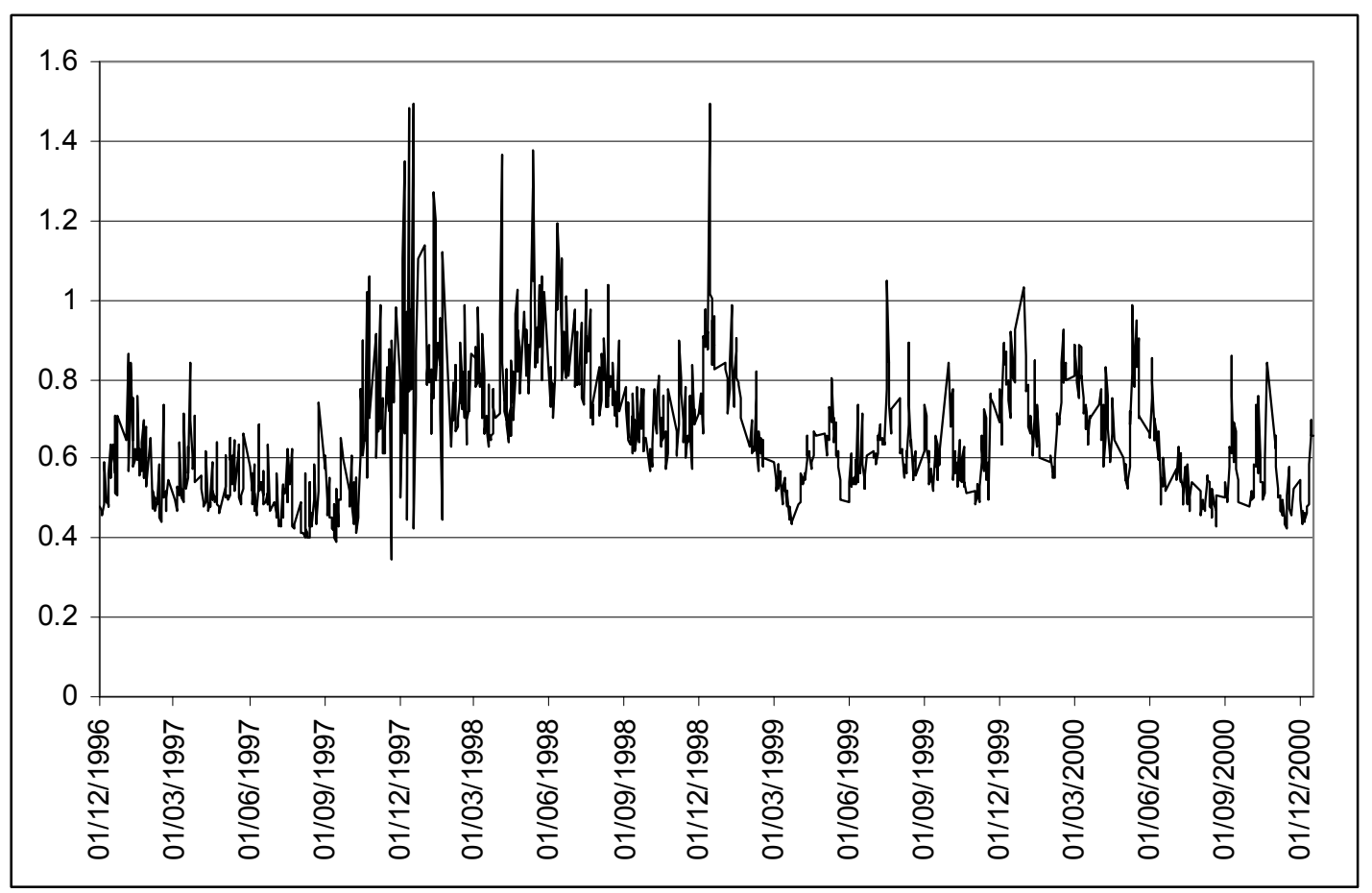

(d) Daily Share Turnover (\%)

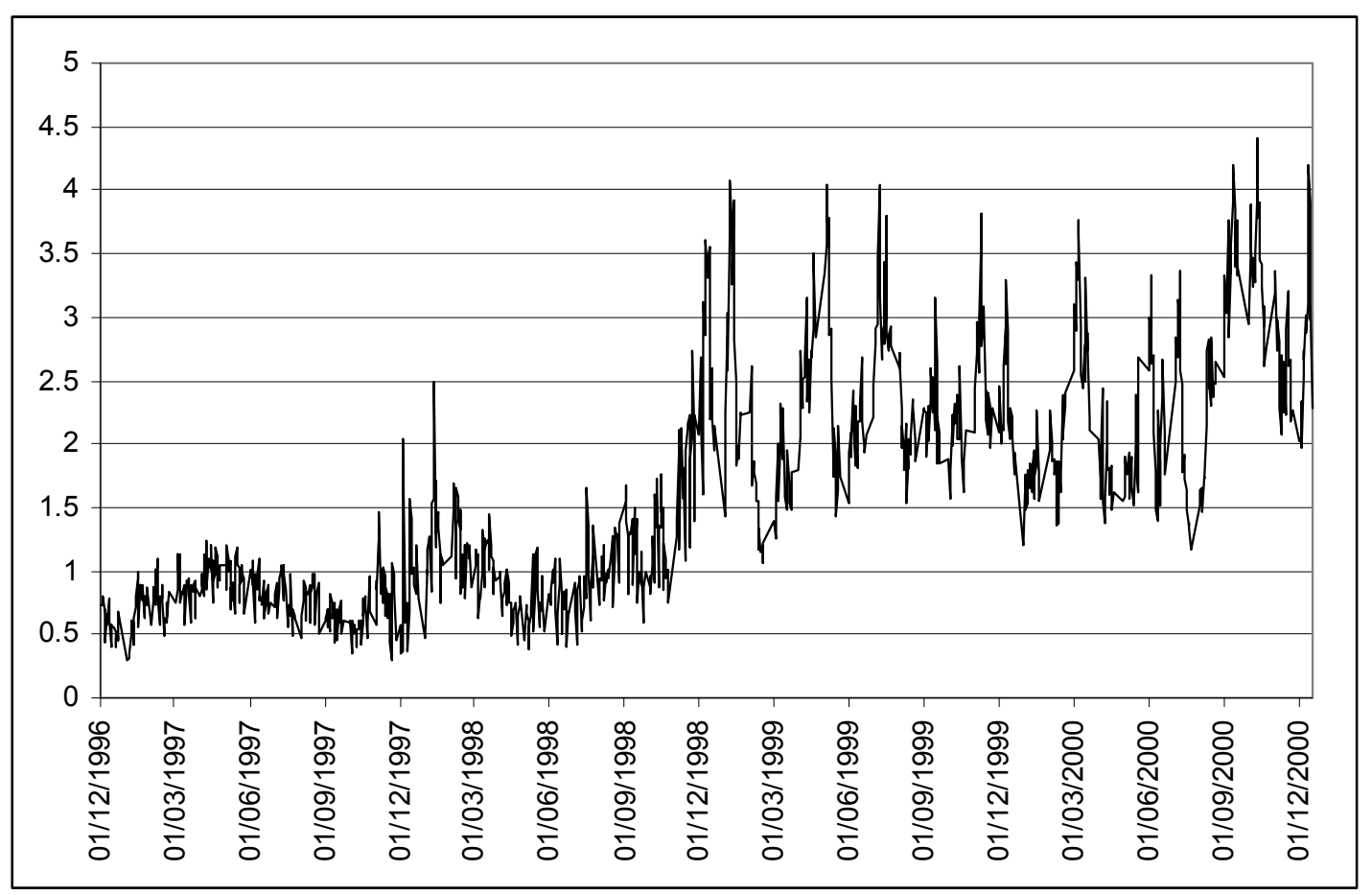


(e) Ratio of Margin Buying Orders to Total Buy Orders (\%)

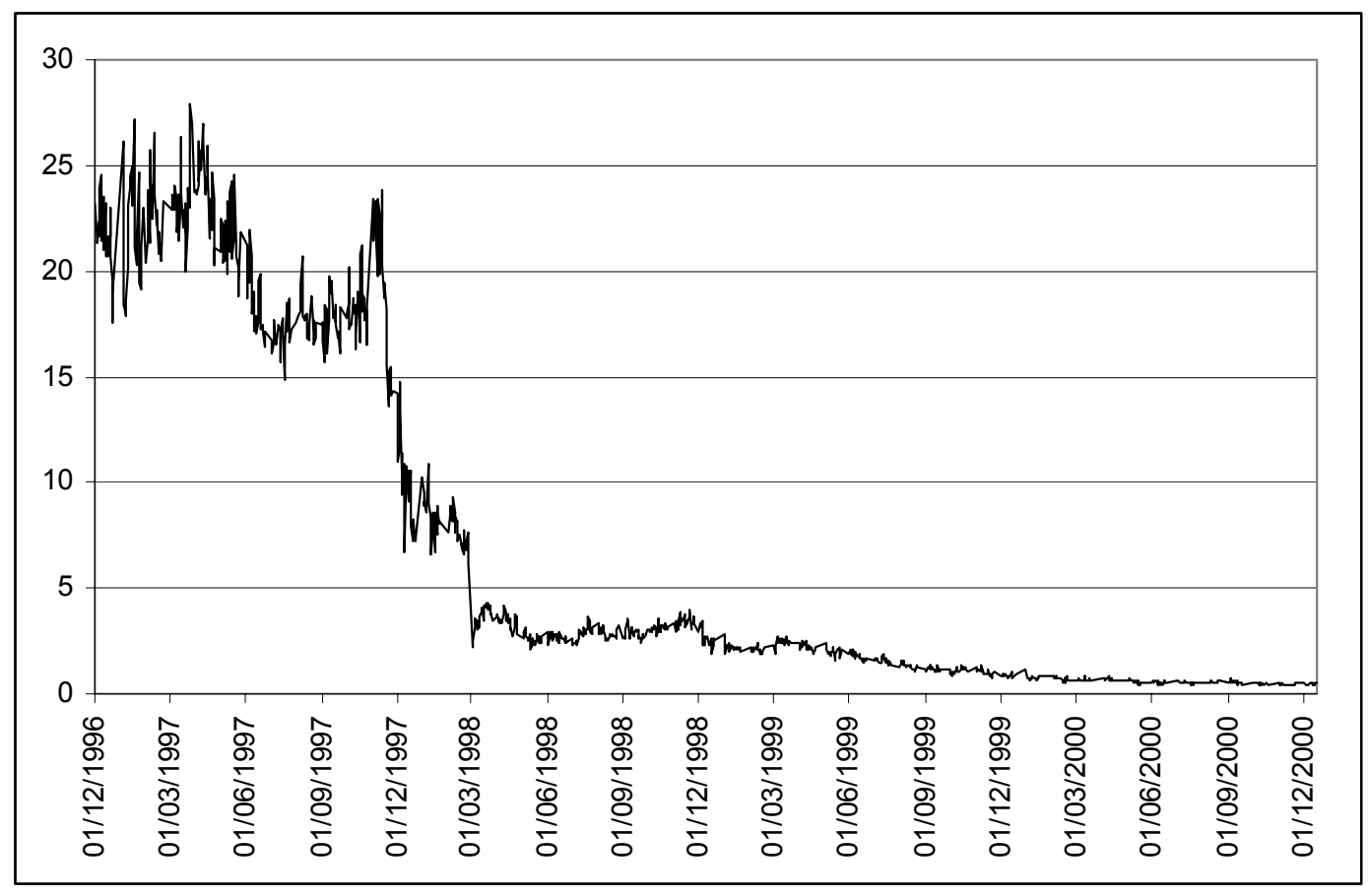

(f) Ratio of Short Sale Orders to Total Sell Orders (\%)

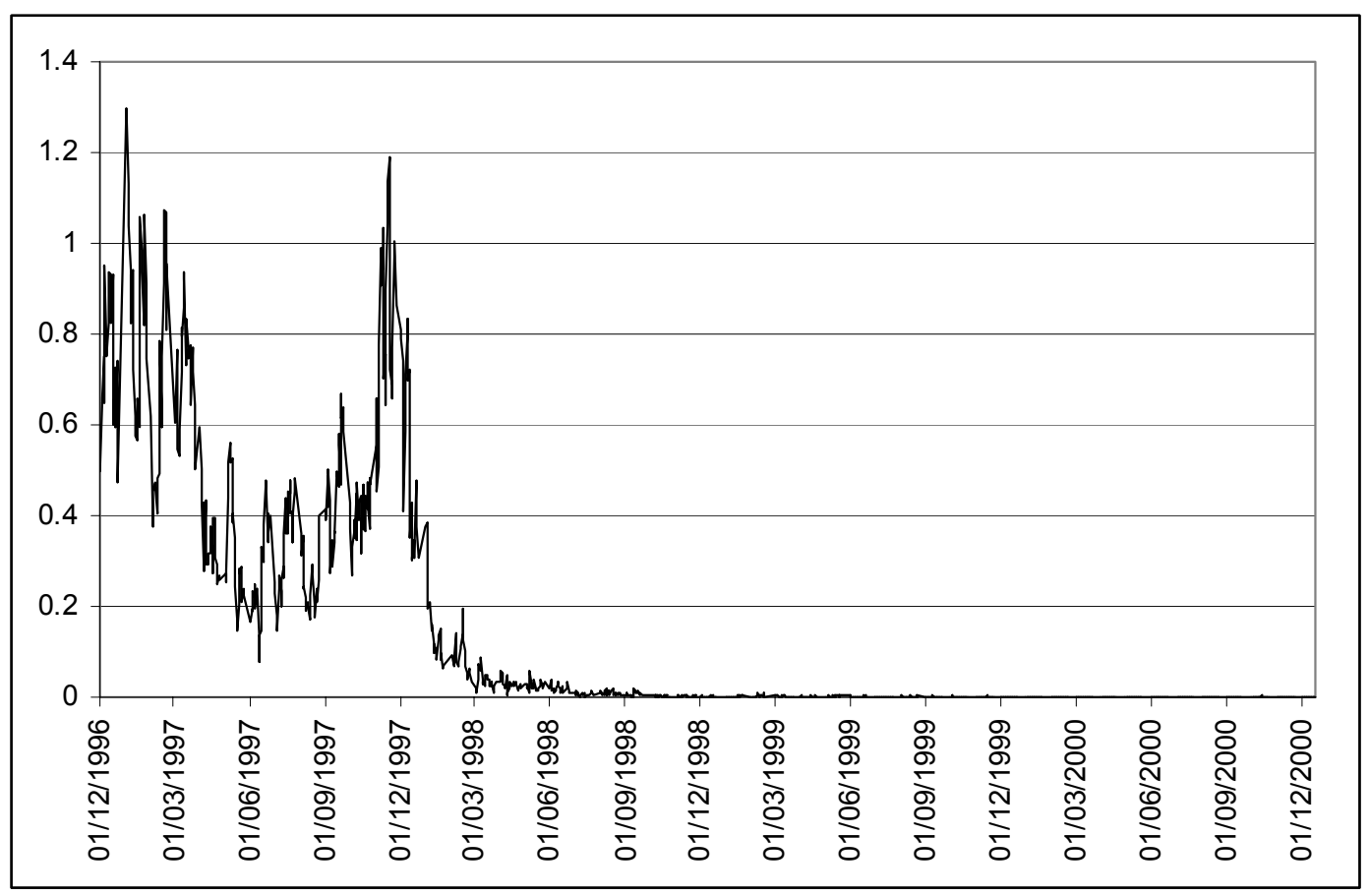

